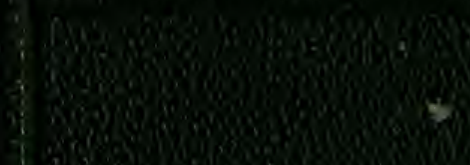




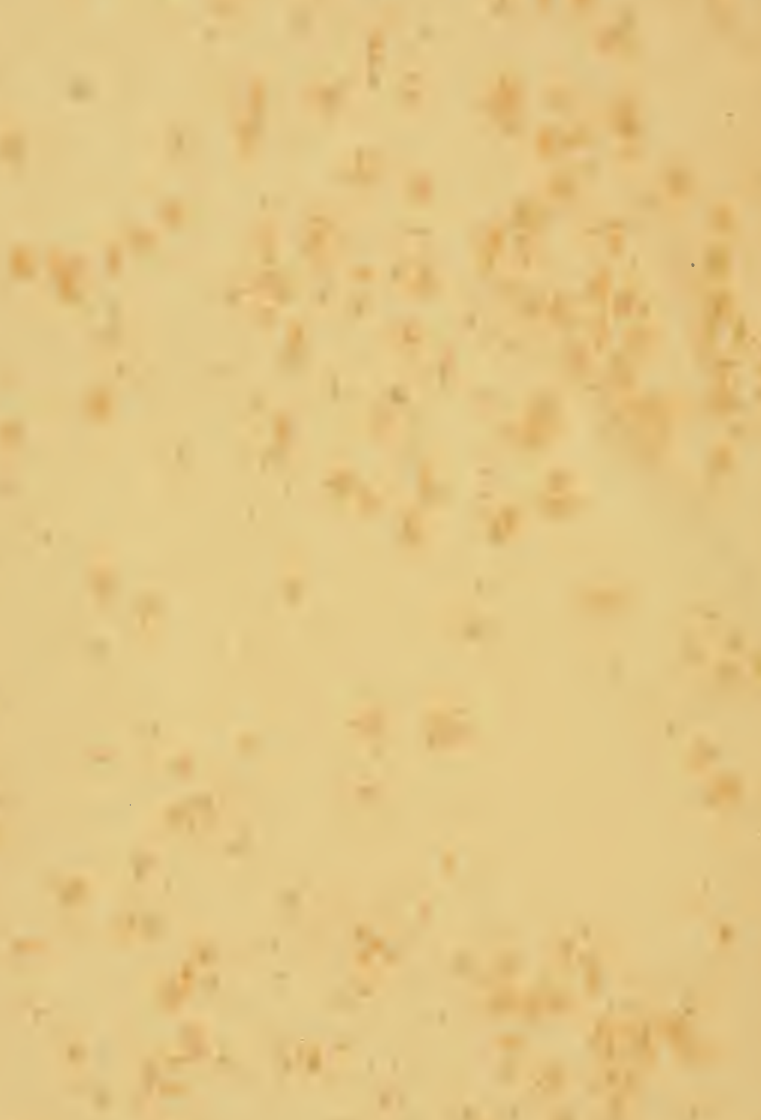




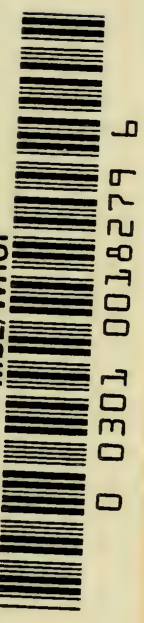




\section{A LABORATORY MANUAL OF THE}

ANATOMY OF THE RAT 


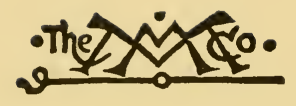

THE MACMILLAN COMPANY

NEW YORK - BOSTON - CHICAGO - DALLAS

ATLANTA - SAN FRANCISCO

MACMILLAN \& CO., Limited

LONDON - BOMBAY - CALCUTTA

MELBOURNE

THE MACMILLAN CO. OF CANADA, LTD. TORONTO 


\section{A LABORATORY MANUAL}

OF THE

\section{ANATOMY OF THE RAT}

\section{BY \\ HARRISON R. HUNT, PH.D.}

PROFESSOR OF ZOÖLOGY

IN THE MiCHIGAN AGRICULTURAL COLLEGE

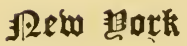

THE MACMILLAN COMPANY

1924

All rights reserved 
COPYRIGHT, 1924,

BY THE MACMILLAN COMPANY.

Set up and electrotyped.

Published December, 1924.

Printed in the United States of America by $J$, J. LITTLE AND IVES COMPANY, NEW YORK 


\section{PREFACE}

Rats can usually be obtained in large quantities in any community if proper trapping methods are used; consequently the rat provides an excellent subject for dissection at colleges in communities where cats or dogs are difficult to obtain. This manual was written to supply laboratory guidance in the study of the rat because it is an inexpensive mammal which is easy to obtain.

The literature on the gross anatomy of this rodent is not extensive. Much of the material in the manual is therefore the result of the writer's own investigations, which were carried on at intervals at the University of Mississippi since the summer of 1920 . No attempt has been made in the text to indicate those sections which are wholly the result of the author's work or those for which information was obtained from other sources.

Instructors can use the manual for elementary classes by omitting those sections which they deem of lesser importance, or it can be used in its entirety for classes in advanced vertebrate anatomy. Illustrations have been purposely omitted, because it is better for the student to get his visual impressions from the animal itself. Either the wild Norway rat or its albino variety may be used.

Acknowledgment for limited assistance is due to Martin and Moale's "Handbook of Vertebrate Dissection," Part III (1884). The writer extends special credit and thanks to Mrs. Eunice Chace Greene, formerly of the zoölogical teaching staff of Smith College, who has very generously read 
nearly all the manuscript, comparing it with her own unpublished researches on the rat, and has called the author's attention to a considerable number of errors, which have been corrected; she has also supplied much unpublished additional information from her own investigations. Credit is due to Dr. Albert M. Reese of West Virginia University for having suggested that the author write this manual, and for much encouragement during its development. In addition, the writer wishes to thank Mr. Frazier Cochrane of Milligan College, and Mr. Joseph W. Stack of the Michigan Agricultural College, for reading the manuscript.

There are doubtless a few errors in fact and nomenclature. I will be very grateful to any critical user of the manual who will report these errors to me.

HARRISON R. HUNT.

East Lansing, Michigan.

November, 1924. 


\section{CONTENTS}

PAGE

External Aspect of the Rat

The Skeletal System • • • • • • • • . 6

The Muscular System • . . . . . . . 38

The Salivary Glands . . . . . . . . 48

The Vascular System • . • • . . 50, 66, 97

The Respiratory System . • • . . . . . 63

The Digestive System . . . . . . . . . 68

The Urogenttal System • • . • . . • • 84

The Nervous System . . . . . . . . 103

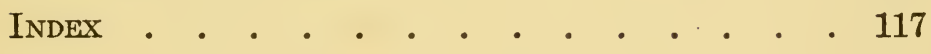



A LABORATORY MANUAL OF THE ANATOMY OF THE RAT 



\section{A LABORATORY MANUAL OF THE ANATOMY OF THE RAT}

\section{INTRODUCTION}

THE rat is one of the few wild mammals that thrives in civilized communities. It reproduces rapidly, consumes or otherwise destroys millions of dollars worth of property, and is the known, or probable, carrier of several parasites harmful to man. Some of these parasites are: Leptospira ioterohaemorrhagiae, the spirochaete organism of infectious jaundice; germs which cause diseases in man following rat bites, for instance rat-bite fever; the tapeworm Hymenolepis diminuta, and possibly its relative $H$. nana; the round worm, Trichinella spiralis, which causes trichiniasis; and Bacillus pestis, the germ of plague. It is claimed that the plague, or "black death," killed 25,000,000 people in Europe during the fourteenth century, and that plague has caused the death of nearly $9,000,000$ persons in India alone since 1896. The rapidity and ease with which rats can be bred has led to their extensive use in experiments by physiologists, geneticists, and others. It is evident, then, that an elementary knowledge of the habits, functions, and structures of the rat is of interest to the medical student, anatomist, agriculturist, and experimental zoölogist.

The rat belongs to the order Rodentia, which includes over one-third of all existing species of mammals. Rodents possess long, chisel-like, eurved incisor teeth (usually but two in the upper jaw, and never more than two in the lower), which grow continuously. The enamel is restricted 
to the front of the incisor, so that in gnawing the softer dentine is worn away at the tip faster than the enamel, thus keeping the tooth sharp. There are no canine teeth. Rodents are mostly herbivorous in diet, are usually small, and have clawed digits. The family Muridae, to which rats and mice belong, is said to include nearly half the genera of the Rodentia.

Four common species of this family are found in the United States. The common house mouse (Mus musculus) is less than two hundred millimeters in length when adult. The generic designation Epimys has been established for the rats, but the older term Mus is doubtless more familiar. Mus rattus rattus (the black, or house rat) is the rat of the Middle Ages in Europe. It probably reached that continent some six hundred years before the Norway rat arrived. The black rat preceded the Norway rat in North America, and occurs still in scattered localities in the northern United States. Its diagnostic characteristics are: the ears when laid forward extend at least to the middle of the eye; the tail is longer than the head and body; and is dusky all around; hind foot 33-37 millimeters; the color is blue-black above, and slaty below. A color variety, Mus rattus alexandrinus (roof, snake, or Alexandrian rat) is "grayish-brown above, white or yellowish white below" (Lantz). It is said to be common in the southern states near the coast. Mus norvegicus (the brown, gray, barn, wharf, sewer, or Norway rat) has, as a result of its adaptability, fecundity, strength, and ferocity, largely replaced the other species of rats in temperate climates. When well fed it is said that a female Norway rat can give birth to from sixty to a hundred young a year. It is more of a burrower than the black or roof rat, and is the common form found about barns, houses, warehouses, etc., in the United States. This species' characteristics are: "Ears moderate, 
when laid forward barely or not reaching eye; tail shorter than (rarely equal to) the length of head and body, darker above than below; color of body normally grey-brown above, white below; hind foot 38-46 millimeters" (Lantz). The common albino rat (Mus norvegicus albinus) is a variety of the Norway rat, and is now known only as a domesticated animal. Mus rattus also has been known to produce albinos. The large number of wild Norway rats that can usually be caught in human communities, together with the ease with which albinos can now be secured from dealers, makes the Norway rat a convenient form for laboratory study by large classes. Either the wild Norway rat or its albino variety can be used for dissection in connection with the directions and descriptions contained in this manual. 


\section{EXTERNAL ASPECT OF THE RAT}

Kill two adult rats with ether or chloroform. One of these is to be used for the study of the muscles, the other for the dissection of the remaining soft parts. Examine the external characteristics of the dead animal and determine the species to which it belongs by referring to the descriptions of species given above. Observe the general form of the trunk, and the characteristic shape of the head. Note the exposed, sharp, chisel-like, canine teeth which the rat uses in gnawing hard objects. The long hairs, or vibrissae, which project laterally from the animal's snout doubtless serve as feelers. Rats in the daytime appear to have poor vision while in the open, for their movements are then uncertain or slow. But when in contact with a wall, for instance, they run rapidly, indicating that they are then assisted by tactile stimuli through the vibrissae. The limbs are comparatively short, each being terminated by five digits (fingers on the fore limbs, toes on the hind ones). The thumb (pollex), which is so inconspicuous that it may be overlooked at first, bears a flattened, nail-like claw, but the claw at the end of each of the remaining four fingers is sharpened. The hind foot has five clawed digits. Numbering these digits from the median side, the first (hallux) and the fifth are shorter than the other three. Observe and determine the numbers of the footpads, or plantar tubercles, on the ventral surfaces of the fore and hind feet. In feeding on a morsel of food, rats are said to assume a sitting posture, and to hold the food between the fore paws while gnawing at it, like a 
squirrel. Note the scales on the tail. How are they arranged? Are scales characteristic of mammals? In what groups of vertebrates are scales usually found?

The anus, or opening through which the residual materials (feces) from the digestive tube pass, is immediately ventral to the base of the tail. The conspicuous swelling ventral to the anus of the male rat is the scrotum, which contains the two testes. Sometimes the testes lie up in the body cavity instead of in the scrotum, in which case the size of the latter is very much reduced. The external opening of the male's urogenital system is located midventrally near the anterior end of the scrotum. Carefully insert one blade of a pair of scissors into this orifice and slit the skin, lengthwise of the animal, for three or four millimeters. Note that the foreskin (prepuce), which is hairy externally, surrounds the distal end (glans) of the penis. Examine now the corresponding region of the female. There are three openings in the female: the anus, ventral to the base of the tail; ventral to the anus is the vaginal orifice, or exit from the female reproductive organs; below this orifice the opening from the excretory system at the distal end of a prominent elevation. How do the relations between these openings in the female rat compare with the corresponding openings in other female mammals?

Carefully observe the hair color of your animal. If you are working with a wild rat scrutinize the distribution of the pigment within individual hairs. Is each hair of the same color throughout? Compare the hair color of the rat with that of other wild animals, if they are available either alive or mounted. Compare the color of the albino's eyes with the eye color of the wild rat.

If time permits, sketch the lateral view of the dead animal. 


\section{THE SKELETAL SYSTEM}

Animals possess two kinds of skeleton. The exoskeleton, found among the Arthropods, covers the outside of the body, protecting the delicate internal organs, and assisting in locomotion by providing surfaces for the attachment of muscles. The disadvantage of an exoskeleton, like that of a crayfish, is that growth must be accompanied by periodic molts to permit of increase in body size. Vertebrates possess an endoskeleton, which is completely inclosed by the soft parts of the body. The endoskeleton supports the body and thereby preserves its general form. It facilitates locomotion by providing levers which are moved by the contraction of the muscles. The skull protects the delicate structures of the brain, while the ribs prevent injury to the organs of the thorax. One important advantage of the endoskeleton is that it does not interfere with growth, for the bones of the vertebrate body increase in length, width, and thickness as the soft parts grow.

The axial skeleton of a vertebrate comprises the skull, backbone, ribs, and sternum. The appendicular skeleton consists of the pectoral and pelvic girdles, the fore legs, hind legs, and feet.

\section{THE SKULL}

The skull of the higher vertebrates is a bony case completely surrounding and protecting the delicate tissues of the brain. It incloses and protects the olfactory organ, 
and the inner and middle ears. It offers some protection to the eyes also. The ventral part is modified to form the upper and lower jaws which are used in grasping, killing, and chewing the food. The skull may be divided into two parts, the cranium, which surrounds the brain, and the visceral skeleton. The latter includes some of the bones of the face, of the upper and lower jaws, some of the bones on the lateral surface of the head in the ear region, and the small sound transmitting bones of the middle ear. The visceral skeleton of the rat is doubtless a highly modified heritage from the fish-like ancestors of the mammals. The chief function of the visceral skeleton of the fishes is to support the gills and lend strength to the jaws. The student should familiarize himself, either through works on evolution, or with the aid of the instructor, with the probable changes by which the visceral skeleton, epiglottis, and the laryngeal and tracheal cartilages of the mammals have evolved from the visceral arches of fishes. Wilder's "History of the Human Body" discusses this question.

The parts of the skull develop in two ways. The floor, and a portion of the sides and back of the cranium consist of bones which have developed from centers of ossification in the embryonic cartilage of these regions. These are the cartilage bones. The roof of the cranium, the remainder of the sides, the hard palate, and the bones of both jaws are intramembranous in origin. They are therefore called membrane bones.

Dorsal aspect of skull. The skull is long and narrow, gradually decreasing in width from the posterior to the anterior end. The width of the human skull is relatively greater, as compared with the length, than the width of the rat skull. The ratio of cranial width to length, or the cephalic index, is an important characteristic in the classification of the races of man. The irregular lines on the 
surface of the rat's skull are the sutures where the adjacent bones are joined to one another.

The extreme posterior, or nuchal, surface of the skull is nearly perpendicular to the long axis of the animal, and joins the dorsal surface almost at a right angle. The lambdoidal ridge occupies the region of union of these two surfaces. It is semicircular in form. Anterior to the lambdoidal ridge is a second ridge extending ventrally to the region of the ear. Dorsally this second ridge joins the temporal line at right angles. This line extends forward laterally on the dorsal surface of the cranium to the orbit, where it turns medially and disappears. Compare the rat with the horse and eat, for instance, where the lambdoidal ridge is well developed, and with the human skull where it is absent.

The orbito-temporal fossa is a deep depression on each side of the mid-region of the eranium, about one-third as long as the whole cranium. It contains the eye, eye muscles, and muscles, which help close the jaw. The zygomatic arch bounds it laterally. This arch is a bowshaped bar of bone which extends forward from the articulation of the lower jaw. At its anterior end this arch broadens and is piereed by the large infraorbital fissure. Viewed from the anterior end this fissure is shaped somewhat like a palm-leaf fan, broad dorsally and narrow ventrally. In other vertebrates the orbito-temporal fossa is more or less completely separated by bony processes into two distinct eavities, the orbit for the eye and its muscles, and the temporal fossa.

The anterior nares [piriform aperture in man] are located at the anterior extremity of the cranium. Air enters through these openings and is conveyed through the nasal passages to the lungs.

The following bones may be seen from the dorsal side: 


\section{THE SKELETAL SYSTEM}

the occipital, interparietal, parietals, frontals, nasals, premaxillaries, maxillaries, zygomatics, squamosals, and lacrimals. The position and structure of each of these bones will be described in detail later.

Exercise I. Draw and label the dorsal view of the skull.

Lateral aspect of the cranium. The nuchal plate bears ventrally the occipital condyle, by which the skull articulates with the backbone. The jugular process is a long, pointed, triangular structure lateral to and slightly in front of the occipital condyle. Between the two is a semicircular depression, the jugular fossa. The mastoid portion of the petrosal bone is immediately anterior to the jugular process, and is located in a pronounced depression of the lateral part of the occipital bone. The tympanic bulla is a hollow spheroidal capsule anterior to the jugular process, opening to the outside through the external acoustic meatus. This opening is closed in life by the tympanic membrane, which transmits sound waves from the outer ear to the three small bones of the middle ear.

Where the mastoid portion connects anteriorly with the squamosal bone there is a ventral extension of the latter, the post-tympanic hook, which helps to hold the tympanic bulla in place.

The orbito-temporal fossa and zygomatic arch are seen from the lateral side also. Within the fossa are foramina through which the nerves emerge from the brain. The foramen ovale is located directly ventral to the posterior end of the zygomatic arch, and anterior to the tympanic bulla. A branch of the fifth cranial nerve emerges here. The foramen communicates by a perforation of the external pterygoid process with the ventral surface of the skull. Another small foramen is immediately in front of the foramen ovale. A few millimeters anterior to the foramen 
ovale is the large anterior lacerated foramen. The optic foramen for the passage of the second cranial nerve is anterodorsal to the anterior lacerated foramen.

There is a pronounced groove along the ventral side of the orbito-temporal fossa. The small postpalatine foramen communicates near the center of this groove with the ventral surface of the palatine bone. Anterior to this foramen another foramen establishes a connection between the orbit and the nasal eavity. A small foramen dorsal to these openings perforates the cranium just posterior to the cribriform plate, which is described later.

The maxillary bone is incompletely ossified medial to the infraorbital fissure. Consequently in cleaning the skull the nasal cavity is usually opened at this place.

The convex lateral surface of the premaxillary bone reveals the course of the root of the enormous curved incisor tooth. The root occupies a semicircular canal (alveolus) which extends back to the level of the infraorbital fissure. Compare the arrangement of the rat's teeth with that of the cat, dog, and man, for instance. The rat has no canine teeth, which are so prominent in carnivores, and no premolars. The three molar teeth are inserted in the maxillary bone a considerable distance posterior to the incisors. The toothless space between the incisor and molar teeth is the diastema. A similar arrangement occurs in the horse, for instance.

Exercise II. Draw and label the lateral view of the cranium.

Ventral view of the skull. The following bones are seen from this view: the occipital, which is flanked on either side by the petrosal bone and the tympanic bulla, the basisphenoid with an alisphenoid fused to each side, the presphenoid and the paired squamosals, palatines, maxillaries, and premaxillaries. 
At the posterior end of the skull is the foramen magnum, through which the brain connects with the spinal cord. On each side of this foramen is the occipital condyle. Two pairs of bony plates, the pterygoid processes, arise at the base of each alisphenoid bone. The outer plates are nearly horizontal in position. They extend from the posterior end of the maxillary bone caudad and laterad to the lateral surface of the tympanic bulla. The two inner pterygoid processes are vertical to the base of the cranium. Each extends posteriorly to the opening of the bony canal through which the Eustachian tube passes from the cavity of the middle ear (within the tympanic bulla) to the pharynx. The single posterior naris, or choana, lies between the anterior extremities of the inner pterygoid processes. It leads forward into the nasal cavity, which opens at the anterior end of the head through the two anterior nares.

The roof of the mouth in front of the choana consists of three pairs of bones (palatines, maxillaries, and premaxillaries), which taken together constitute the hard palate. At the extreme posterior end of the hard palate are the two small palatine bones, which form the ventral boundary of the choana. The maxillary bones are considerably larger than the palatines and are located laterally and anteriorly to the latter. The lateral, or alveolar, portion of the maxillary bears the three molar teeth, which are used for grinding food. The maxillaries articulate in front with the premaxillaries. These bear the two large curved incisor teeth. Canine and premolar teeth are absent in the rat.

Several pairs of foramina appear on the ventral surface. The twelfth (hypoglossal) cranial nerve emerges through the hypoglossal canal at the base of the occipital condyle. The posterior lacerated foramen lies immediately in front of the hypoglossal canal, at the boundary between the 
petrosal and occipital bones. This foramen transmits the ninth (glossopharyngeal), tenth (vagus), and eleventh (accessory) cranial nerves. The carotid foramen is anterior to the jugular foramen, between the tympanic bulla and the basioccipital bone. Near the posterior ends of the pterygoid processes is a pair of foramina which communieate with one another by a horizontal space in the basisphenoid bone. A large oval foramen lies immediately anterior to the one just mentioned. Note the communication of this oval foramen with the superior orbital fissure. Ventral to the foramen ovale another large oval foramen perforates the posterior part of the lateral pterygoid process. Note the two slits in the cranium, dorsal and posterior to the choana, communicating with the anterior lacerated foramen.

The prepalatine foramina are two conspicuous slits on the roof of the mouth in the region of the diastema. They are surrounded by the maxillary and premaxillary bones. The postpalatine foramina perforate the roof of the mouth near the lateral margin of each palatine bone. A bristle inserted through the foramen will show its communication with the groove on the floor of the orbito-temporal fossa.

Exercise III. Draw and label the ventral view of the cranium.

Interior of the cranium. Bisect the skull vertically in a plane slightly at one side of the sagittal plane. Use a sharp bone saw with small teeth. Care should be exercised to injure the bones as little as possible.

Two cavities will be observed, the cranial cavity for the brain, and the nasal cavity. The cranial cavity is subdivided further into the cerebellar, cerebral, and olfactory fossae.

The cerebellar fossa holds the cerebellum. It occupies the posterior part of the cranium and is partially sepa- 
rated from the cerebral fossa by an incompletely ossified lateral partition, the tentorium. The ossified portion of the tentorium is a dorsal extension of the petrosal bone, which forms a part of the lateral wall of the cerebellar fossa. The floccular fossa is a relatively large cavity occupying the posterodorsal region of the petrosal bone. Its opening into the cranial cavity is an oval aperture considerably narrower than the cavity itself. The cerebral fossa is the largest division of the cranial cavity. It incloses the cerebrum. The foramina observed in the study of the lateral view may be identified easily by thrusting a bristle through each foramen from the outside. The olfactory fossa is a laterally compressed cavity opening behind into the cerebral fossa and bounded in front by the cribriform plate. This cavity contains the olfactory lobes of the brain. The branches of the olfactory nerve enter the nasal cavity through the numerous foramina in the cribriform plate. In a cranium from which the roof has been removed, the cribriform plate will be seen to be heartshaped.

Though the nasal eavity can be satisfactorily studied in a longitudinal section of the skull, it can be seen to the best advantage if the dorsal and lateral bony wall of the cavity be removed. In doing this care should be taken to preserve intact the nasal bones and their delicate ventral processes, and while chipping away the lateral wall to injure as little as possible the delicate turbinal bones at the back and sides of the nasal cavity. The nasal eavity is tubular in form posteriorly (naso-pharyngeal duct), and terminates at the single posterior naris, or choana. Its external opening is through the two anterior nares at the anterior end of the snout. The nasal cavity is bounded dorsally by the nasal bones, posteriorly by the cribriform plate and maxillary bones, ventrally by the premaxillary, 
maxillary, and palatine bones. The two long prepalatine foramina lie in its floor, and it communicates by a foramen with each orbito-temporal fossa. A perpendicular median partition, the nasal septum, divides the nasal cavity into two nasal fossae. The septum is partly cartilaginous.

Each nasal fossa contains three very delicate, folded turbinal bones, which probably correspond to the maxilloturbinal, nasoturbinal, and ethmoturbinal bones of other mammals. The first of these is an elongated thin sheet of bone attached ventrally to the inner surface of the premaxillary bone. The second is a process of the nasal bone. Its ventral edge turns outward and upward like the rolled edge of a stiff piece of paper. The ethmoturbinal bone is much more extensively convoluted than the other turbinals. The convolutions inclose spaces known as ethmoidal cells, whose long axes are, in general, directed anteroposteriorly. The ethmoturbinals are attached posteriorly to the cribriform plate. Examination of a skull in which the bone has been removed from the side of the nasal fossa shows that in the posterior part of the fossa the turbinal bones extend from the top to the bottom of the cavity and posteriorly almost to the optic foramen. The convolutions of the turbinal bones, together with the flesh covering them, are sometimes called the nasal labyrinth. In mammals the folds supported by the turbinals warm the air and extract foreign bodies from it. The epithelium covering the ethmoturbinals contains olfactory cells which are stimulated by odorous substances in the air.

Consult a text on comparative anatomy to determine the variations among vertebrates in the bones of the nasal cavity. Compare the nasal cavity of the rat with the same part in the turtle, frog, dogfish, etc. Assisted by a text on embryology outline the stages in the evolution of the nasal cavity. 


\section{Bones of the Cranium}

Having examined the general topography of the skull, the structure of each bone should be studied in greater detail.*

\section{Occipital Bone (Os Occipitale)}

This bone first appears in the mammalian embryo as four centers of ossification in the chondrocranium (cartilaginous cranium). One of these centers is dorsal (supraoccipital), one ventral (basioccipital), and two are lateral (exoccipitals) to the foramen magnum. These four bones fuse in mammals to form the occipital. The supra- and ex-occipital regions in the rat are the posterior wall of the cranium. The basioccipital is the floor of the cerebellar fossa.

The basioccipital region is trapezoidal in shape, broader behind than in front. Anteriorly it joins the basisphenoid bone by a suture at right angles to the long axis of the skull. Posteriorly it forms the ventral boundary of the foramen magnum. Laterally it comes in contact with, but is not fused to, the tympanic bulla and the petrosal bone. Note the two marked depressions on the ventral surface of the bone which are separated from one another by a median ridge. The inner surface of the basioccipital, where it comes in contact with the brain, is concave.

The occipital condyles and the triangular jugular processes previously mentioned, are parts of the exoccipital regions. The condyles bound the foramen magnum ventrolaterally. They articulate with the atlas, or first neck vertebra. This articulation permits the head to be raised

* By boiling in water or an aqueous solution of sodium hydroxide the bones may sometimes be separated along the sutures. Too prolonged boiling in the hydroxide solution will make the bones so fragile that they will easily fall to piees when handled. 
and lowered vertically without a corresponding movement of the neck. The hypoglossal canal is anterior to the condyle. The exoccipitals are fused dorsally with the supraoccipital, ventrally with the basioccipital, and are in contact anteriorly with the mastoid process of the petrosal bone.

Viewed from above the dorsal edge of the supraoccipital region resembles the segment of a circle with its center anterior to the bone. The ends of the segment terminate in a dorsoventral ridge where the supraoccipital connects with the squamosal bone. This ridge is continuous with the post-tympanic hook. A median vertical ridge (the posterior occipital protuberance) bisects the nuchal surface.

\section{Sphenoid Bone (Os Sphenoidale)}

The sphenoid is a complicated structure consisting of two distinct parts, the anterior sphenoid and posterior sphenoid. Each of these, in turn, consists of three elements, separated in some of the lower vertebrates, but fused in the higher.

The three fused elements forming the posterior sphenoid are the single median basisphenoid (post-sphenoid) and the two lateral alisphenoids. The basisphenoid is bounded caudally by the basioccipital, anteriorly by the anterior sphenoid, and laterally is fused with the alisphenoid bones. Anterior to its union with the alisphenoids, the basisphenoid increases slightly in width up to its attachment with the presphenoid. The pterygoid processes (one pair on each side), described in the discussion of the ventral view of the skull, are attached to the ventral surface of each alisphenoid bone. Dorsal to the lateral pterygoid process is a depression into which the foramen ovale and two other foramina open. The alisphenoid expands, dorsal 
to these foramina, into a flat process which extends toward the base of the zygomatic arch. This process runs posteriorly to the tympanic bulla but does not fuse with it. The process joins dorsally the squamosal and frontal bones. It forms a part of the posterior wall of the orbito-temporal fossa, sending a process forward to the palatine bone and alveolar process of the maxillary. The failure of the alisphenoid bones to fuse with the presphenoid. and anterior part of the basisphenoid, leaves a pair of long slits dorsal to the choana. Observe the position of the anterior lacerated foramen.

The three fused constituents of the anterior sphenoid bone are the single median presphenoid and the two lateral orbitosphenoids. The presphenoid bone extends anteriorly from the basisphenoid. In the cerebral fossa its smooth surface decreases in width anteriorly until it is reduced to a thin septum between the two optic foramina. The ventral surface bears a keel which appears as a low ridge on the roof. of the naso-pharyngeal duct. Each optic foramen is bounded medially by the presphenoid, laterally by the wedge shaped orbitosphenoid bone. The base of the latter is fused with the presphenoid. Its apex is thrust outward between the alisphenoid bone, posteriorly, and the orbital process of the frontal bone, anteriorly. The shape and size of the orbitosphenoid can be readily observed from the inside of the cranial cavity.

\section{Squamosal Bone (Os Squamosum)}

The squamosal bone resembles a very short-handled claw hammer if viewed from the lateral surface of the skull. The "handle" widens posteriorly, and with a spur from the occipital bone forms the posttympanic hook. The "handle" is bordered dorsally by the parietal bone, 
ventrally by the petrous and tympanic bones, and by an unossified region of the skull. The "claw" of the hammer is bounded ventroanteriorly by the alisphenoid bone; posteriorly its tip approaches the tympanic bone. Dorsally the "hammer" joins the frontal and parietal bones; it is bounded anteriorly by the orbital process of the frontal bone.

The squamosal bone bears a pronounced longitudinal ridge which runs nearly its whole length. Dorsal to the "claw" the ridge is extended anteroventrally as a curved spur, the zygomatic process. This process forms a part of the zygomatic arch. The mandibular fossa, for the articulation of the lower jaw, lies ventral to the base of the zygomatic process.

\section{Trmpanic Bone (Os Trmpanicum)}

The tympanic bulla contains the tympanic cavity, or cavity of the middle ear, which opens laterally through the external acoustic meatus.

\section{Petrosal Bone (Os Petrosum)}

The petrosal bone incloses the inner ear, and is seen on the inner surface of the skull. The mastoid portion of the petrosal is inserted into the notch at the side of the occipital bone.

\section{INTERPARIETAL BONE (Os INTERPARIETALE)}

The interparietal is an ovoid bone of membranous origin inserted between the supraoccipital and the paired parietals. It meets the nuchal surface nearly at right angles. 


\section{Parietal Bone (Os Parietale)}

The paired parietal bones are of membranous origin. They constitute the greater part of the roof and a considerable part of the sides of the cerebral fossa. Each bone, were it flattened out, would be nearly rectangular. The true shape is obscured externally by a process of the squamosal bone which covers the anteroventral part of the parietal. Note the connections, posteriorly with the interparietal, anteriorly with the frontal, and laterally with the squamosal bones. The curved inner surface is smooth, but externally the temporal line separates the dorsal from the lateral region of each bone.

\section{Frontal Bone (Os Frontale)}

The two frontal bones are of membranous origin. They are united in the mid-dorsal line by the frontal suture. Each bone consists of a frontal and an orbital part. The former roofs the skull in front of the parietals, the latter forms the greater part of the side wall of the orbito-temporal fossa. The temporal line sharply separates these two portions of the bone externally. The frontal part joins the parietal bone posteriorly at the coronal suture. This part decreases in width anteriorly and articulates with the nasal and premaxillary bones. The orbital part is concave. Its posterior region, partly overlaid by the squamosal bone, forms a portion of the back wall of the orbit. Ventrally it joins the alisphenoid, orbitosphenoid, and maxillary bones-anteriorly the lacrimal and maxillary bones.

The frontal bones, internally, are the anterior wall of the cerebral fossa, the lateral wall of the olfactory fossa, and they partly inclose the nasal cavity posteriorly. An 
internal ridge marks the boundary between the cerebral and olfactory fossae. The cribriform plate is attached to the frontal bones between the olfactory fossa and nasal cavity.

\section{EтHMOId Bone (Os Ethmoidale)}

This highly complicated bone, of cartilaginous origin, is the chief representative of the embryonic nasal capsule. It includes the perpendicular plate of the nasal septum, the cribriform plate, and the ethmoturbinal bones.

\section{Maxillary Bone (Maxilla)}

The maxillary bone consists chiefly of five processesthe frontal, zygomatic, alveolar, palatine, and orbital. It is a membrane bone. The frontal process is divided by the large infraorbital foramen into a lateral and median portion. The latter forms part of the lateral wall of the nasal cavity and is comparatively thin. The skull is unossified posterior to this part of the frontal process, which joins the premaxillary bone dorsally and anteriorly. The lateral portion of the frontal process is a laterally concave plate connected with the dorsal surface of the cranium by a bony arch. To the dorsal end of this plate is attached the zygomatic process, which forms the anterior half of the zygomatic arch. The alveolar process (so called because it contains the alveoli of the teeth) is a strong bony mass holding the three molar teeth. It is bounded posteriorly and dorsomedially by the sphenoid bones, medially by the palatine process and palatine bone. The palatine process joins its fellow on the opposite side by a median suture in the roof of the mouth. It forms part of the hard palate. In front it surrounds the posterior half of the prepalatine foramen. It joins the pala- 
tine bone posteriorly. The orbital process overlaps the anteroventral portion of the frontal bone's orbital process. It forms but a small part of the wall of the orbito-temporal fossa. A pronounced longitudinal groove on the floor of the fossa partly separates the orbital from the alveolar process.

\section{Lacrimal Bone (Os Lacrimale)}

The lacrimal bone is a thin inconspicuous element, of membranous origin, lying on the dorsomedial wall of the infraorbital foramen. It is immediately below the bony arch which connects the dorsal surface of the skull with the lateral part of the maxillary bone's frontal process. The bone is easily overlooked if its sutures are not exposed by careful scraping.

\section{Premaxillary Bone (Premaxilla)}

The premaxillary bone, of membranous origin, forms the anterior part of the upper jaw, and the lateral and ventral walls of the front part of the nasal cavity. With the nasal bone it surrounds the anterior nares. Its frontal process is thrust dorsally between the nasal and maxillary bones, extending eaudally to the frontal bone. This process is partially overlaid laterally by the maxillary bone. On the ventral side the palatine process extends horizontally across the roof of the mouth, surrounding the anterior part of the prepalatine foramen and meeting its fellow at a median suture. This suture extends backward between the two maxillary, as well as between the palatine bones. The premaxillary bears an enormous incisor tooth. Carefully chip away the bone surrounding this tooth, and note the size and shape of the alveolus. The palatine process joins the palatine process of the 
maxillary bone. The process is attached to the vomer along the median suture of the hard palate. The vomer forms part of the nasal septum. The elongated maxilloturbinal bone attaches to the inner surface of the premaxillary. It lies lengthwise of the nasal cavity and extends upward from its line of attachment.

\section{Zygomatic Bone (Os Zygomaticum, Malar, Jugal)}

The zygomatic bone is a small bow-shaped element of membranous origin, joining the zygomatic processes of the maxillary and squamosal bones, thus completing the zygomatic arch.

\section{Vomer, or Ploughshare, Bone}

This fragile bone, which is membranous in origin, comprises the ventral portion of the nasal septum. It unites ventrally with the premaxillary bone. It splits dorsally into two longitudinal lamina, between which the cartilaginous part of the nasal septum is inserted. The posterior part of the bone is without a ventral attachment.

\section{Nasal Bone (Os Nasale)}

The nasal bones roof the anterior nares and the nasal cavity back to the frontal bones. The ventral surface is concave, both the lateral and the median borders bearing a flange. The median flanges of the two nasals unite to form a ridge for the attachment of the nasal septum. The lateral flange articulates with the frontal process of the premaxillary bone. This flange is widest where the nasoturbinal bone (see longitudinal section of the skull) is attached to it. The line of attachment of the nasoturbinal runs forward and medially from this point. The nasal bone is a membrane bone. 


\section{Palatine, or Palate, Bone (Os Palatinum)}

The palatine bone, membranous in origin, consists chiefly of three elements-the horizontal part, and the orbital and sphenoidal processes. The horizonal part constitutes the posterior region of the hard palate, and therefore is the ventral boundary of the choana. It meets its fellow of the opposite palatine bone at the median suture along the dorsal side of the mouth cavity. Laterally it articulates with the alveolar process of the maxillary bone. The orbital process, which joins the horizontal part nearly at right angles, is exposed to the orbito-temporal fossa. It constitutes the greater part of the nasopharyngeal duct's lateral wall. The dorsal edge articulates with the presphenoid bone. The sphenoid process extends backward to the pterygoid process, and joins dorsally an anterior extension of the alisphenoid bone.

\section{The Mandible (Mandibula)}

The mandible comprises two lateral elements united in front by connective tissue at the mandibular symphysis. Each element contains five parts: the body, the ramus, and three processes attached to the latter posteriorly. The body of each half of the mandible is prolonged anteriorly as a strong, curved process bearing one large incisor tooth. This tooth projects anterodorsally a considerable distance beyond the bone. Behind the incisor is the diastema, a toothless region corresponding to the diastema of the upper jaw. A row of three molar teeth is posterior to the diastema. The two rows of molars are approximately parallel to each other, but each row forms an acute angle with the long axis of the bone in which it is inserted. There are transverse ridges on the grinding surfaces of the molars. The ramus is the laterally flattened region immediately 
behind the body. Three processes are attached to its posterior end. The coronoid process projects dorsally into the orbito-temporal fossa. Just behind this is the condyloid process, bearing an elongated rounded knob which articulates with the mandibular fossa of the squamosal bone. These articular surfaces in the rodent permit anteroposterior motion of the jaw. The angular process is directed posteriorly. The anterior mandibular incisure is a pronounced depression separating the coronoid from the condyloid process. The posterior mandibular incisure likewise separates the condyloid and angular processes. The mandibular foramen lies at the base of the condyloid process. The mental foramen lies ventroanteriorly to the molar teeth. Other foramina occur on the surface of the mandible. A ridge extends on the lateral surface of the mandible from the mental foramen backward to the border of the angular process. The medial surface of this process is concave. The incisor tooth of the lower jaw, like that of the upper, is sickle-shaped, and inserted in a large dental alveolus which extends caudally, ventral to the molar teeth, nearly to the base of the condyloid process. The mandible is largely a membrane bone.

\section{Hyoid Bone (Os Hyoideum)}

The hyoid is a $u$-shaped bone at the base of the tongue composed of a slender transverse body and two pairs of horns (cornua), one pair extending anteriorly, the other pair posteriorly.

Exercise IV. Make a labeled sketch of each of the bones of the head.

\section{THE VERTEBRAL COLUMN}

The vertebral column, or backbone, is the second division of the axial skeleton. It is a linear series of numerous 
vertebrae, each one fastened to its neighbor by connective tissue. The back-bone supports the neck, trunk, and tail, and to it are attached the ribs, pelvic girdle and numerous muscles. It comprises seven cervical, thirteen thoracic, six lumbar, four sacral, and about twenty-eight caudal vertebrae.

A typical vertebra possesses a solid, more or less cylindrical ventral portion, the centrum, or body. The vertebral, or neural, arch is attached to the upper side of the body, the two inclosing the vertebral foramen, through which the spinal cord passes. The roots of the vertebral arches (pedicles) are the two lateral vertical plates of the vertebral arch. The two horizontal plates forming the roof of the arch are the laminae. The neural spine, or spinous process, projects upward from the junction of the laminae. The vertebra bears on each side a transverse process. The spinous and transverse processes serve for the attachment of spinal muscles. Each vertebral arch bears two pairs of articular processes, or zygapophyses. Of these the anterior one, or prezygapophysis, articulates with the preceding vertebra; the posterior surface, or postzygapophysis, articulates with the succeeding vertebra.

The essential features of the vertebral column may be brought out best by describing vertebrae from each region of it. The seven cervical vertebrae are quite similar to one another, except the first two, the atlas and epistropheus (axis). The atlas is essentially a ring of bone. It lacks a centrum, this element having been separated from the atlas and attached to the epistropheus as the dens (odontoid process). This process rests in a semi-circular depression, the fovea dentis, on the ventral floor of the atlas. The dorsal surface of the atlas bears a tubercle comparable to the spinous process of an ordinary vertebra. The ventral surface bears a similar tubercle. The atlas articulates 
with the occipital condyles of the skull by means of two lateral concave surfaces, the superior articular foveae, one on each side. It bears posteriorly a pair of lateral ovoid surfaces, inferior articular foveae, for articulation with the epistropheus. A third articular surface connects these facets ventrally. In man, and presumably in the rat, the chief movement permitted between the superior articular foveae and the occipital condyles is a "nodding" of the head. In "shaking" the head the atlas revolves around the dens as a pivot. The elongated transverse process of the atlas is flattened dorsoventrally. Its dorsal surface slopes backward to the posterior end of the vertebra, where it joins a vertical plate. Between this plate and the inferior articular fovea is the posterior opening of the foramen transversarium, through which the vertebral artery passes. This foramen extends anterodorsally, and communicates with the dorsal surface of the atlas by an oval opening. The artery then turning medially traverses the atlantal foramen to the inner surface of the atlas.

The centrum of the epistropheus is flattened dorsoventrally and prolonged anteriorly by the dens. The dens articulate with the fovea dentis by the anterior articular facet on its ventral side. The cranial articular facets, one on each side of the epistropheus, impinge upon the inferior articular foveae of the atlas. The postzygapophyses, one toward the upper end of each pedicle, articulate behind with the prezygapophyses of the third cervical vertebrae. The laterally flattened neural spine is considerably higher than that of any other cervical vertebra. It extends forward over the atlas and backward over the third vertebra. The foramen transversarium pierces the base of the short transverse process.

In the fifth cervical vertebra the centrum and vertebral arch form in side view an obtuse angle with each other. 
The centrum is dorsoventrally flattened. The spinous process is a low pointed crest. The prezygapophysis, borne by the pedicle, is ovoid when viewed from above. Its articular surface is directed dorsomediad. The postzygapophysis is directly behind it, is similar in shape, and its articular surface is ventrolaterad. The transverse process, attached at the base of the pedicle, is pierced in the region of attachment by the foramen transversarium. The vertebrarterial canal comprises the transverse formina of the cervical vertebrae. It terminates with the sixth cervical vertebra.

The centrum of the fifth thoracic vertebra is nearly cylindrical. The spinous process is long and tapering; its point is directed caudally. There is a notch on the anterior edge of the laminae. This notch is flanked on each side by the oval prezygapophyses whose articular surfaces face dorsally. The postzygapophyses lie behind the prezygapophyses, but their articular surfaces are directed ventrally. Each pedicle is deeply notched posteriorly, forming an intervertebral foramen, for the passage of a spinal nerve. The transverse process of each side is situated between the anterior and posterior zygapophyses. The articular surface of the transverse process, facing laterally, supports the tubercle of a rib. A depression, the costal demifacet, will be observed at each end of the centrum near its dorsal border. The adjacent demifacets of two successive vertebrae combine to form the articular surface for the head of a rib. The tubercle of this rib articulates with the posterior vertebra of the pair under consideration.

The fourth lumbar vertebra's centrum is cylindrical ventrally, but flattened above. The spinous process is a laterally compressed plate which runs the whole length of the vertebra, is somewhat triangular in shape, and leans 
cranially. The articular surface of the prezygapophysis faces mediodorsad. The facet of the prominent postzygapophysis faces laterally. The transverse process projects cranioventrally from the base of the pedicle.

The sacrum consists of four vertebrae more or less completely fused together. The transverse processes project horizontally from the centra. They are fused at their distal ends. The transverse processes of the first two sacral vertebrae are considerably thicker than the others. They are expanded laterally, forming the auricular surface, which articulates with the pelvic girdle. Since this girdle is attached to the hind legs, the weight of the posterior part of the body falls on these two sacral vertebrae-hence their stout construction. The intervertebral formina are located, as usual, between the vertebrae. The prezygapophyses of the first sacral vertebra are well developed, for they are part of a movable joint. The remaining functionless zygapophyses of the sacrum are rudimentary. They lie close to the bases of the high spinous processes.

The caudal, or tail, vertebrae show gradual and progressive stages of simplification from the sacrum to the posterior end of the tail. The neural canal is small in the anterior part of the tail, and soon completely disappears. The anterior caudal vertebrae have ventral pairs of spines between which run the caudal blood vessels. There is a chevron bone in some of the vertebrae which partly incloses these vessels on the under side.

Exercise $\nabla$. Make a labeled sketch of each vertebra which has been described.

The sternum, or breastbone, comprises seven bony segments (sternebrae) united end to end. The first, or manubrium, is keeled ventrally, and has a broad anterior region, concave above. The first rib is attached to it. The suc- 
ceeding six pairs of ribs are attached between the segments. The seventh segment (xiphoid process) is not associated with a pair of ribs. It terminates in a round plate of cartilage.

Exeroise VI. Draw and label the sternum.

There are thirteen pairs of ribs. A rib contains a dorsal and a ventral segment. The anterior seven pairs are the true ribs, for they are attached to the sternum. The six posterior pairs are the false ribs. The eighth, ninth, and tenth pairs attach to the posterior border of the seventh, and by cartilage to the fifth sternebra. The three posterior ribs are floating ribs, lacking ventral segments. The ribs are bow-shaped in general, the angle, or region of greatest convexity, being dorsal. Most of the ribs are distinctly flattened anteroposteriorly. From the fifth to the tenth pairs, inclusive, the distal end of the rib is twisted, so that the broad surface is posterolaterad. Compare the shapes of the different ribs.

The fifth rib may be used to illustrate the articular surfaces. The capitulum costae (head) is a slight swelling at the proximal end. Its circular medial surface articulates with the demifacets of two adjacent vertebrac, as previously described. The tuberculum costae (tubercle) is a dorsal enlargement two or three millimeters lateral to the head. It articulates with the transverse process of the vertebra, and is separated from the head by the collum costae (neck) of the rib.

The thoracic cavity, surrounded on the sides by the ribs, dorsally and ventrally by the backbone and sternum respectively, resembles an ice cream cone with the apex cut off. The cranial thoracic aperture is in front, the larger caudal thoracic aperture behind. Both are circumscribed by ribs, sternum, and backbone. The thoracic cavity in- 
creases in size, and air enters the lungs, when the ribs are pulled anteriorly in breathing.

Exercise VII. Sketch one of the longer ribs.

\section{THE ANTERIOR APPENDAGES}

The pectoral girdle includes the scapula (shoulder blade), and the clavicle (collar bone). The former is a flattened triangular bone with its apex pointing cranioventrad and its broad inner surface facing the vertebral column. A cartilaginous disc connects one end of the clavicle with the acromion process of the scapula. A similar disc unites the other end with the anterior end of the sternum. The clavicle is the only bony connection between the scapula and axial skeleton.

The concave thickened superior margin of the scapula is directed cephalad. The convex vertebral margin is dorsal. The third margin, the axillary, faces ventrocaudally, and is nearly straight. The anterior, posterior, and ventral corners of the bone are designated the medial, inferior, and lateral angles respectively. At the lateral angle is the pear-shaped glenoid cavity for articulation with the humerus bone of the upper arm. The short coracoid process (homologous to the bone of the same name in the lower animals) projects medially from the cranial end of the glenoid cavity. The scapular spine is a thin, prominent plate (forming nearly a right angle with the scapula) which divides the lateral surface of the scapula into the supraspinous fossa (anterior) and the concave infraspinous fossa (posterior). The spine tapers dorsally to a point at the vertebral border; it ends ventrally in a free projection, the acromion process or acromion. The inconspicuous projection on the caudal surface of the latter is probably the metacromion process. There are two longitudinal ridges on the inner surface of the scapula. 
The humerus is the bony constituent of the upper arm. Its proximal end articulates with the scapula; it articulates distally with the radius and ulna of the fore arm. Between these two extremities is the shaft, or body, of the bone. The head is a prominent oval enlargement at the proximal end, which fits into the glenoid cavity, furnishing the articulation with the scapula. The lesser tuberosity is a low knob located immediately in front of the head on the medial surface of the bone. The greater tuberosity is a dorsoventrally elongated projection on the cranial surface of the humerus, immediately in front of the head, extending also on to the lateral surface of the bone. The intertubercular groove separates the two tuberosities. The deltoid tuberosity is a very prominent rough-edged ridge running, on the ventral surface, from the greater tuberosity about half way to the distal end of the humerus.

The articular surface at the distal end of the bone is saddle-shaped to receive the corresponding surfaces of the radius and ulna. This end of the bone is flattened. It bears two depressions immediately above the articular surface-the radial fossa on the ventral side to receive the radius during flexion of the arm, and the olecranon fossa on the dorsal side to accomodate the olecranon process during extension. The medial epicondyle is a prominent cylindroid process medial to the saddle-shaped articular surface. The lateral epicondyle is a broad process located laterally near the distal end of the bone.

The radius and ulna support the fore arm, the former lying anterior to the latter. The two are firmly bound together by the interosseus ligament. The body of the radius bows forward and outward. Dorsally it expands abruptly, forming the head, which bears an oval surface for articulation with the humerus. The posterior side of the head is flattened, and rests against a similar surface 
just below the semilunar noteh of the ulna. The radius is expanded distally to articulate with the wrist, or carpal bones. Longitudinal grooves eross this expansion; medially it bears the pointed styloid process.

The ulna is laterally compressed, the lateral surface bearing a pronounced groove extending from the level of the head of the radius two-thirds of the way to the distal end. Like the radius, the ulna bows forward and outward, so that an articulated skeleton looks "bow-legged." The ulna terminates distally in the conical, blunt styloid process for articulation with the wrist bones. The semilunar notch is the saddle-shaped depression near the proximal end, which, with the head of the radius, articulates with the humerus. The flat surface at its ventral border corresponds to the radial notch of other animals; it articulates with the head of the radius. The olecranon is the stout projection behind the semilunar notch for the insertion of the extensor muscles of the upper arm.

The joint between the humerus and scapula is of the "ball and socket" type, permitting of lateral as well as anteroposterior movement. The elbow joint, however, is of the hinge type, which permits only of extension and flexion of the arm.

There are nine carpal or wrist bones. The metacarpal bones are the relatively long bones in the palm of the hand. Counting from the medial side of the manus, the third and fourth are the longest, the fifth is considerably shorter, while the first is so short as to be readily mistaken at first glance for one of the carpal bones. Each digit contains three phalanges, except the thumb (pollex), which contains two. Each terminal phalanx bears a claw, that of the thumb being flattened like a nail.

Exercise VIII. Draw and label the lateral view of the scapula and the bones of the fore limb. 


\section{THE POSTERIOR APPENDAGES}

The two coxal bones (os coxae), sometimes called the innominate bones, comprise the pelvic girdle. Each bone is firmly united dorsally to the two anterior sacral vertebrae. Ventrally the two are held together by connective tissue at the pubic symphysis. The lateral surface of each bone bears a deep pit, the acetabulum, for the reception of the head of the thigh bone (femur). Unlike the pectoral girdle the direct attachment of the pelvic girdle to the backbone furnishes a rigid support for the strong and active hind legs of the animal. The coxal bone consists of three fused elements, the ilium, ischium, and pubis, which radiate from the acetabulum. The distal ends of the pubis and ischium are also fused, so that these two bones surround an oval space, the obturator foramen. Though the sutures are completely obliterated in the adult, they can be very easily seen in a very young animal. The cartilaginous boundaries between the three bones in such an animal all lie in the acetabular wall, though the end of the pubis forms only a very small part of this wall. The distal connection of pubis and ischium will be observed at the ventral extremity of the obturator foramen. The acetabular wall of the adult is well supported with bone. The acetabulum itself is funnel-shaped. The inner, or constricted portion, of this funnel expands medially to form a dorsoventrally elongated pit.

The ilium (os ilium) is the anterior branch of the triradiate coxal bone. It consists of two parts, the body and the wing. The former is somewhat flattened laterally, forms the anterior part of the acetabulum, and bears the anterior inferior spine on its lateral surface just in front of the acetabulum. The greater sciatic notch is a depression along the dorsal border of the ilium, extending back 
on to the ischium. Its anterior border is the posterior inferior spine. The iliopectineal line on the ventral side of the body connects the sharp anterior border of the pubis with the wing of the ilium. The wing is the broad, flat, anterior part of the ilium. The posterior part of its concave medial surface is the auricular surface, which articulates with the sacrum. Anterior to this surface the ilium bends outward rather abruptly, terminating in a pronounced tuberosity at right angles to the long axis of the bone. The thickened anterodorsal margin of the bone is the iliac crest.

The ischium (os ischium), the most posterior component of the coxal bone, has three parts: a body, a superior ramus, and an inferior ramus. The anterior end of the bone forms the posterior side of the acetabulum. The body expands posteriorly, giving off dorsally the superior and ventrally the inferior ramus. This part of the ischium is concave medially, and convex laterally. The inferior ramus joins the pubis at the ventral extremity of the obturator foramen. There is a longitudinal depression along the dorsolateral surface of the ischium. This depression is bounded ventrally by a longitudinal ridge, terminating posteriorly in a thickening, the sciatic tuber. The upper edge of the ischium is convex, while the posterior edge is nearly a straight line. These two edges meet at almost a right angle.

The pubis (os pubis) is the ventral branch of the coxal bone. Its superior ramus extends ventrally from the acetabulum. The inferior, or symphyseal, ramus passes back along the symphysis pubis to join the inferior ramus of the ischium. The body is located at the region of union of the two rami. The sharp anterior edge of the bone bears the iliopectineal eminence. From this the iliopectineal line passes forward. 
The femur, or thigh bone, consists of a long body with processes at each end for attachment of muscles, or for articulation with other bones. The proximal end is $\mathrm{Y}$-shaped. The medial branch of the $\mathrm{Y}$ is capped with a hemispherical knob, the head, which fits into the acetabulum. The head is held in place by the round ligament (ligamentum teres femoris) of the femur, attached to the center of the articular surface. The head is joined to the shaft by the narrow cylindrical neck. Head and neck together resemble a small "toad stool," the neck corresponding to the stalk of the "stool." The massive lateral branch of the $\mathrm{Y}$, the great trochanter, is continued as a high thin ridge down the lateral surface of the femur. This ridge is sometimes referred to as the third trochanter, and the lateral branch of the $\mathrm{Y}$ as the first trochanter, the two being considered components of the greater trochanter. The lesser or second trochanter is a knob ventral to the base of the neck on the flexor surface of the femur. The intertrochanteric crest connects the greater and lesser trochanters. The trochanteric fossa is a deep depression at the base of the medial side of the greater trochanter. The lateral and medial condyles are large ventral swellings at the distal end of the femur. They are separated from each other by the deep intercondyloid fossa, which is continued on to the extensor surface of the bone as the grooved patellar surface for articulation with the patella. The two condyles articulate with the proximal end of the tibia.

The tibia extends from the knee to the ankle. The fibula is a slender bone posterior to the tibia. The two are anchylosed in the lower third of the tibia. These two bones resemble an archer's bow, the fibula representing the cord, the forward bending tibia the wooden bow. The shaft or body of the tibia decreases in thickness distally. Beyond the anchylosis it is cylindrical in cross section, but 
triangular proximal to this point. Thus the bone presents three surfaces: a coneave anterolateral surface, a convex anteromedial surface, and a posterior surface with two pronounced longitudinal grooves. A ridge, the anterior crest, is located proximally on the anterior side of the bone at the angle formed by the lateral and medial surfaces. The bone articulates with the femur proximally. The articular surface is divided into two large concave condyles, separated from each other by a longitudinal groove, the intercondyloid fossa. Each of these is opposed to the convex surface of one of the femoral condyles. The tibia and fibula articulate distally with the talus (astragalus) bone of the heel. The tibial part of the articular surface contains two longitudinal grooves, separated by a ridge. The medial malleolus forms the medial boundary of the inner groove. The fibula bears the lateral malleolus upon its lateral surface. The slender fibula expands dorsally, where it is attached by a ligament to the external condyle of the tibia.

The patella is a sesamoid bone lying in front of the knee joint.

The tarsus, or ankle, contains eight bones arranged in two rows, one distal and one proximal, with one bone between the rows. The proximal row contains the talus and calcaneus. The talus articulates with the tibia and fibula. The calcaneus, or heel bone, is shovel-shaped and is the largest bone in the tarsus. The "handle," or heel process, is directed posteriorly, forming the support for the heel. When the toes are depressed the trochlea of the talus acts as a fulcrum, the heel process as a lever moved by the posterior leg muscles. The length of the heel process makes it a relatively efficient lever. There are also four sesamoid bones in the tarsus. There are five long, cylindrical metatarsal bones in the foot, those of the great toe, or 
hallux, and of the little toe being shorter than the remaining three. Each toe, or digit, possesses three phalanges, except the hallux, which has two. Each terminal phalanx ends in a curved claw.

Exercise $I X$. Make a labeled drawing of the lateral view of the innominate bone and the bones of the hind limb. 


\section{THE MUSCULAR SYSTEM}

The function of muscular tissue is to produce movement of parts by contraction. Contraction may or may not be under the control of the will. The action of voluntary muscles is consciously controlled; involuntary muscle is not so controlled, and a person is usually not cognizant of its activities. These two types of muscle tissue differ also in microscopic structure, form, and distribution. They are alike in that the structural unit in each case is the muscle fiber, which is a cell highly differentiated for the function of contraction.

Involuntary, or nonstriated, muscles are found in the walls of the digestive tract, arteries and veins, bronchial tubes, uterus, bladder, in the glands, etc. The fibers are either more or less scattered or disposed in sheets. Each fiber is an elongated, spindle-shaped cell, containing a single, centrally located nucleus, and a longitudinally striated cytoplasm. They are under the control of the sympathetic nervous system, and they contract much less rapidly than voluntary muscles.

The striated muscle tissue comprises the skeletal muscles for the movement of the arms, legs, trunk, jaw, and head, the eye muscles for rotating the eyeballs, the muscles of the face, etc. With the exception of the striated muscles of the esophagus, the somewhat differently constructed muscles of the heart, and a few others, striated muscles are voluntary. The fibers are very long as compared with their diameter. The sarcolemma, or thin outer wall of the fiber, incloses the sarcoplasm, in 
which the longitudinal fibrils are imbedded. Alternate light and dark regions in these fibrils produce the cross striated appearance. Each fiber contains many nuclei, but it is believed by some to be a single cell. The nuclei occur near the surface in the "white" muscles, or deeper in the fiber between the fibrils in the "red" muscles. "Red" muscles contract more slowly than the "white," and are more resistant to fatigue.

Striated muscle fibers are aggregated into bundles, fasciculi, and these in turn into masses of varying size and shape, known as muscles. In general these fibers run parallel to one another, and are bound together into bundles by connective tissue. The contraction of the muscle is initiated by a nervous stimulus. The energy for muscular work is derived from chemical changes in carbohydrates, proteins, and fats. These are conveyed by the blood to the muscles. Heat is generated by muscular contraction. Carbon dioxide and other waste products of muscular work are carried away by the blood.

As a rule a muscle is attached at each end, the less movable attachment being the origin; the more movable is the insertion. The attachment may be by means of a tendon, a non-elastic cord sometimes of considerable length, or by a sheet of connective tissue, an aponeurosis. A compound muscle has several origins or insertions. Sometimes parts of a tendon may ossify, producing a sesamoid bone, such as the patella. The fleshy portion of a muscle is called the belly.

Most muscles move bones and cartilages, though some may induce movement in soft parts only, such as the facial muscles which pass from a bone to the easily movable skin. Some which lie beneath a concave or convex surface merely tend to straighten out this surface when they contract. The processes of many of the bones act as levers moved by 
the muscles attached to them, while adjacent articulations of the bones are fulcra. There are three classes of these levers in the body: (1) those in which the fulcrum lies between the muscular attachment and the resistance; (2) the fulcrum at one end, muscle at the other, the weight between; (3) or the fulcrum may be at one end, with the muscle attached to the middle, and the weight at the other end of the bone. Examples of case 2 are rare in man. The nearer the muscle attachment is to the fulcrum, the greater must be the force of contraction to move the lever. Mechanical advantage is secured in machines by having a small force act through a great distance at the end of a long lever, moving a heavy object a short distance. In the musculo-skeletal system this arrangement is generally reversed, a powerful muscular contraction acting at the end of a shorter lever to cause rapid movement of a small weight at the end of a longer lever. Efficiency is sacrificed for speed.

The extensor muscles straighten a member, like the arm or finger. Flexor muscles bend it. Rotators turn it on its axis. Abductor muscles bend the part away from the median line of the body or limb; adductor muscles cause the reverse movement. As suggested by the names, a levator muscle lifts a structure, a depressor depresses it. A sphincter muscle surrounds an opening, which is closed when the muscle contracts. The function of dilators is to expand such an orifice.

To prepare a rat for the study of the muscles, lay it on its back and make a midventral longitudinal cut through the skin extending from the external genitalia to the tip of the jaw. Cut no deeper than the skin, to avoid injuring the underlying muscles. In the same way slit the skin on the median surface of the front and hind legs, extending the euts to the midventral incision. Remove the skin. 
Great care should be exercised to avoid removing the cutaneous muscles, which are located immediately under the skin. The student should be provided with two rats, one for the study of the muscles, the second for the dissection of the remaining soft parts. Only the larger superficial muscles are included in the following account.

\section{MUSCLES OF THE SKIN}

The cutaneous maximus muscle spreads out fanwise from the region of the arm pit. It covers the back from the shoulders to tail, the sides of the trunk posterior to the front leg, and a large part of the ventral surface of the trunk. Its function is to move the skin, in which it is inserted.

The platysma is a thin sheet of muscle which radiates from the posterior angle of the mouth, covers the posterior side of the face and the lateral surface of the neck, and sends a branch up in front of the ear. The broad cervical portion is attached along the middorsal line of the neck.

Exercise $X$. Sketch the cutaneous maximus and platysma muscles into an outline drawing of the lateral view of the rat.

Carefully remove the two preceding muscles.

\section{SUPERFICIAL MUSCLES OF THE HEAD} (LATERAL VIEW)

Masseter. This muscle consists of two main parts, an external and an internal. Anteriorly these two are distinct, but they blend posteriorly.

Internal part. Origin, the whole length of the zygomatic arch. Insertion, the mandible, posterior to the diastema. Anteriorly the fibers run nearly at right angles to the long axis of the jaw; posteriorly they form an acute angle with this axis. 
External part. Origin. It is attached anteriorly to the skull in an elongated pit ventral to the base of the zygomatic process of the maxillary bone. From here a strong flat tendon passes backward over the outer surface of the internal part of the muscle. It originates posteriorly from the posterior half of the zygomatic arch. The anterior and posterior regions blend posteriorly with one another and with the internal part. Insertion, the mandible.

This muscle is a powerful elevator, raising the lower jaw. The anteroposterior fibers, especially of the external part, presumably draw the jaw forward in gnawing.

Temporal Muscle. This is a powerful muscle occupying the posterior part of the orbito-temporal fossa and the side of the head behind it. Origin: the temporal line, the posttympanic hook, the lateral surfaces of the parietal and squamosal bones, and the posterior wall of the orbitotemporal fossa. Insertion: the coronoid process and the other parts of the mandible. It elevates the lower jaw.

The Quadratus Labii Superioris Muscle is a triangular structure whose apex is at the anterodorsal angle of the orbito-temporal fossa; it is inserted at its broad end into the whisker pad.

\section{SUPERFICIAL MUSCLES OF THE NECK, SHOUL- DER, AND UPPER FORE LIMB (LATERAL VIEW)}

Levator Auris Longus Muscle. It extends from the middorsal line of the neck as far forward as the back of the head, to the base of the auricle of the ear. It pulls the auricle dorsocaudad.

Acromiotrapezius Muscle. Origin, the spines of all the cervical and first four thoracic vertebrae. Insertion: (1) the clavicle; $(2)$ the acromion process and lateral edge of the spinous process of the scapula.

Clavotrapezius Muscle. Origin, the medial half of the 
clavicle. Insertion, the lateral part of the crest that runs dorsally from the external auditory meatus.

Sternomastoideus Muscle. This muscle is anterior, and parallel to, the clavotrapezius. Origin, the anterior end of the manubrium. Insertion, by a tendon to the mastoid bone.

Spinotrapezius Muscle. Origin, (1) the spines of the fourth to the thirteenth thoracic vertebrae; (2) from the lumbodorsal fascia from the level of the thirteenth thoracic to the third lumbar vertebra. Insertion, the scapular spine. It draws the scapula dorsocaudad.

Latissimus Dorsi Muscle. This is a triangular muscle attached at one of its angles to the medial side of the humerus. Origin: the spines of the thoracic vertebrae from the eighth to the twelfth, inclusive, and the lumbodorsal fascia to the level of the third lumbar vertebra. Insertion, by a strong tendon to the medial surface of the humerus. It is also strongly united to the muscles lateral to it in the axillary region. The fibers converge to the tendon of insertion. It pulls the arm caudodorsad.

Acromiodeltoideus Muscle. Origin, the acromion and metacromion processes of the scalpa, and the ventral border of the clavicle. Insertion, the deltoid process of the humerus. The acromiodeltoideus is bipinnate; the fibers from the clavicle form an acute angle with those from the acromion and metacromion processes where these two groups of fibers join a connective tissue septum ventral to the humerus. This septum forms the connection of the muscle with the deltoid process.

Spinodeltoideus Muscle. Origin, the infraspinous fascia and anterior two-thirds of the spine of the scapula. Insertion: it is united ventrally by an aponeurosis with the free edge of the deltoid tuberosity of the humerus. It flexes the humerus and rotates it outward. 
Triceps Brachii Muscle. This muscle has three headsthe caput longum, caput laterale, and caput mediale.

Caput longum. This head lies on the dorsal side of the upper arm. Origin, the anterior third of the axillary margin of the scapula. Insertion, the olecranon.

Caput laterale. This head lies on the lateral surface of the upper arm. Origin, the larger tubercle of the humerus. Insertion, the olecranon.

Caput mediale. It lies along the dorsal surface of the humerus. It is wedge-shaped, being pointed at the anterior end, but greatly increasing in size posteriorly. Origin, the dorsal and dorsolateral surfaces of the humerus throughout practically the whole ventral surface of the muscle. The pointed anterior end of the muscle reaches nearly to the head of the humerus. Insertion, the olecranon. The caput mediale is not seen superficially, but is found when the caput laterale and caput longum are removed.

\section{SUPERFICIAL MUSCLES OF THE TRUNK}

External Oblique Muscle. This is a very extensive thin muscle situated laterally and ventrally on the thorax and abdomen. Anterior origin : it is attached along the side of the thorax by a muscular slip to each rib from the fourth to the twelfth. Posterior origin, the lumbodorsal fascia. The anterior slips interdigitate with the posterior slips of the serratus anterior. Insertion: (1) it fastens to a fascia on the ventral surface of the thorax and abdomen; $(2)$ is attached along the whole length of the inguinal ligament (a white, stout, slender ligament extending along the angle between the inner surfaces of the hip and body, from the symphysis pubis to the erest of the ilium); (3) a broad branch of the muscle extends back to the symphysis pubis. Carefully expose all parts of the origins and insertions and determine the muscle's probable action by an inspection of its relations. 


\section{SUPERFICIAL MUSCLES OF THE HIND LEG}

Biceps Femoris Muscle. This muscle has three portions, or heads-the anterior, posterior, and accessory. The origin of the anterior head is the last sacral and the first caudal vertebra. The posterior and accessory heads originate at the sciatic tuber of the ischium. All three are inserted by an extensive fascia into the distal end of the femur and the proximal two-thirds of the tibia.

Glutaeus Maximus Muscle. This triangular muscle originates by fascia from the dorsal border of the ilium, from the last three sacral vertebrae, and the first caudal vertebra. It is inseparably united anteriorly with the tensor fasciae latae muscle. Its origin is covered posteriorly by the anterior head of the biceps femoris. Insertion, the third trochanter of the femur.

Tensor Fasciae Latae Muscle. Origin, iliac crest. Insertion, fascia lata of the thigh. This muscle is exposed antero-ventrad to the glutaeus maximus.

Semitendinosus Muscle. Origin, the posterior part of the sciatic tuber. Insertion, by a tendon on the tuberosity of the tibia. It joins the tibia from the medial side. It passes from its dorsal origin down around the posterior side of the thigh on to the medial surface of the shank. Action, flexes and rotates the shank.

Exercise $X I$. Outline the whole body of the rat as seen in the lateral riew, and in this outline draw and label the muscles visible after the remoral of the cutaneous maximus and platysma muscles.

MUSCLES ON THE VENTRAL SIDE OF THE HEAD, NECK, THORAX, AND ABDOMEN

Place the skinned animal on its back, then dissect and identify the following muscles.

Digastricus Muscle. This muscle lies between the mas- 
seters on the lower jaw. Locate its origin on the skull and its insertion on the mandibles at, and near, the symphysis.

Sternohyoideus Muscle. The two sternohyoideus muscles lie on the ventral side of the neck behind the digastricus. They are in contact with one another along the sagittal plane of the neck. Origin, the sternum. Insertion, the hyoid bone.

The sternomastoideus and clavotrapezius muscles have already been mentioned in connection with the lateral view. Identify them here.

Omohyoideus Muscle. This muscle will be observed on the ventral surface of the neck in the triangular space bounded by the digastricus, sternohyoideus, and sternomastoideus muscles. Origin, the superior margin of the scapula. Insertion, the hyoid bone.

The Pectoral Muscles are a prominent group on the ventral side of the thorax. The pectoralis major partially conceals the pectoralis minor. The pectoralis major consists of a superficial and a deeper portion. The origin of the superficial portion is the anterior half of the sternum's manubrium; it is inserted on the deltoid ridge. The deeper portion originates on the manubrium of the sternum and the first and second sternebrae; the insertion is likewise on the deltoid ridge.

Pectoralis Minor Muscle. Remove the pectoralis major to study this muscle. It comprises three parts. The origin of the first, or most anterior, part is the second to the fifth sternebrae, inclusive; insertion, on the coracoid process of the scapula and the lesser tuberosity of the humerus. The second, or middle, portion originates at the fifth sternebra and is inserted on the deltoid ridge. The origin of the third portion is the xiphoid process of the sternum; the insertion is on the coracoid process of the scapula.

Rectus Abdominis Muscle. This consists of a pair of 
thin strap-like muscles along the ventral side of the abdomen and the ventrolateral surface of the thorax. Over the greater part of the abdomen each muscle unites with its fellow by means of the linea alba, along the midventral line. Posterior to the xiphoid process the muscles diverge, running forward ventrolaterally along the thorax. It retracts the sternum and compresses the abdomen. Origin, the posterior part of the pubic symphysis, and the coxal bone in the immediate vicinity. Insertion, the first rib, the manubrium of the sternum, and the clavicle.

Exercise XII. Outline the ventral aspect of the body and draw the muscles into this outline. 


\section{THE SALIVARY GLANDS}

The glands of the neck should be studied first, because they or their ducts are likely to be injured during the dissection of the blood vessels of this region. Cautiously remove the skin from the head and neck, taking care to avoid injuring the underlying muscles, blood vessels, and glands. Removal of the subcutaneous connective tissue on the ventral and lateral surfaces of the neck will now reveal the glands. These are of three types, salivary, lymph, and lacrimal.

The salivary glands secrete the saliva, which is mixed with the food in the mouth during mastication. Look for two of them in the rat, the parotid and the submaxillary glands. The parotid is the rather loosely organized, elongated, mass extending from the base of the external ear along the side of the neck to the ventral surface of it. Find and trace the parotid duct (Stenson's duct) which transports the salivary secretion from the gland to the mouth cavity. The duct is formed by the union of several tributaries from different parts of the gland, traverses the lateral surface of the jaw muscle (masseter), then turns inward to the mouth cavity. The duct should not be confused with the nerves which cross the surface of the muscle in this region. Immediately anterior to the dorsal portion of the parotid is the extra-orbital portion of the lacrimal, or tear, gland. Locate its duct and trace it to the eye. The submaxillary glands are the large elongated pair on the ventral surface of the neck. The median faces of these glands are in contact with one another, in the sagittal plane 
of the animal, throughout most of their length. Trace the two submaxillary (Wharton's) ducts, each of which leaves the anterior end of one of the glands and courses cephalad to the opening on the ventral surface of the buccal cavity. In following the ducts avoid injury to the blood vessels of this region. The masses which lie anterior to the submaxillary glands between the rami of the lower jaw are said to be lymph glands.

Exercise XIII. Sketch a ventrolateral view of the head showing these glands and their ducts. 


\section{THE VASCULAR SYSTEM *}

The vascular system conveys food materials and oxygen to the cells of the body, and carries away from these cells the waste products of metabolism. The food substances dissolved in the blood furnish energy for the cell's activities, and materials for replacing the protoplasm which has disintegrated during metabolism. The blood stream tends also to equalize the temperature throughout the body. Still another function is the conveyance of hormones from their sources to parts of the body whose activities the hormones accelerate or retard.

The vascular system carries two fluids-blood and lymph. The former consists of an almost colorless fluid, plasma, and of red (erythrocytes), and white (leucocytes) blood cells. When clotting occurs the plasma is resolved into the fluid serum, which is incapable of clotting under ordinary conditions, and the solid clot of fibrin. The capacity of blood to form a clot is of primary importance, since it greatly reduces the chance of death through the loss of blood following injury. The red blood cells contain hemoglobin, which has the power of combining with oxygen in the lungs, and carrying it to the tissues, where it is released. Hemoglobin gives the blood its reddish color when exposed to oxygen. There are several types of white blood cells.

* The discussion of the vascular system is divided into three parts, separated from one another by descriptions of other systems. Experience has shown the convenience of studying the heart and blood vessels anterior to it early in the dissection, of examining the hepatic portal system immediately before the abdominal organs are observed, and of postponing the analysis of the vessels posterior to the heart until after the study of the abdominal contents. 
Some of them remove necrotic tissue or other detritus, and therefore function as scavengers. The lymph consists of plasma and white blood cells. The lymph vessels are the parts of the vascular system which transport lymph.

The heart receives blood laden with carbon dioxide (venous blood) from the systemic veins. It pumps this blood to the lungs through the pulmonary arteries. Carbon dioxide is surrendered here and oxygen enters the blood from the air chambers of the lungs. The oxygenated blood then returns to the heart through the pulmonary veins, and is propelled to the body through the systemic arteries. The branches of the arteries terminate in vessels of microscopic size, the capillaries, in which food and oxygen are surrendered to the cells of the muscles, glands, etc., and carbon dioxide enters the blood. The blood from the capillaries ultimately drains into the systemic veins and flows back to the heart. The internal structure of the heart and other details of the circulation will be discussed later.

The arteries and veins in any part of the body may often be dissected simultaneously. This is the logical procedure, since the arteries carrying blood to a part and the veins conducting blood away from it often lie close together. Considerable care must be exercised in dissecting out blood vessels, particularly veins, since they are frequently broken easily. It is better, as a rule, to locate a vessel at one place, then to follow it from that locality into the adjoining tissues just as a workman, having exposed a buried water pipe which he desires to uncover completely, follows it from the point at which it was first located. Every attempt to find a vessel anew at a place where it is concealed by other tissues unnecessarily increases the chance of breaking it accidentally.

The arteries should be injected with a colored fluid immediately after killing the rat. This fluid will force the 
blood out of the arteries, through the capillaries and into the veins, which will therefore be filled, after preservation, with dark coagulated blood. The fluid may be introduced through the left ventricle of the heart.

\section{VEINS ANTERIOR TO THE HEART}

Skin a rat whose blood vessels have been injected, exercising great care to remove nothing but the skin. Do not remove the integument between the hind legs on the ventral and posterior surfaces until ready to study the urinogenital system. Place the skinned animal upon its back and slit the thorax along a line parallel to the sternum but seven or eight millimeters to its left, and extending from the diaphragm to the level of the anterior end of the heart. Continue the incision dorsally along the junction of diaphragm and body wall. Expose the thoracic cavity by pressing this flap outward. The lungs and heart will be seen through this aperture. The membranous attachments of the lungs will not be injured by this dissection if the scissors are not thrust too far into the thoracic cavity. Avoid extending the incision too far forward, as the blood vessels anterior to the heart region will be cut.

Observe the membranous sac (pericardium) surrounding the heart, the large organ in the middle of the cavity. Note the mesentery-like mediastinal septum extending from the diaphragm to the anterior end of the thoracic cavity, and from the pericardium to the sternum. The small pulmonary lobe just behind the heart lies loosely in a chamber inclosed by the diaphragm behind, by lateral membranes extending from the pericardium to the diaphragm, and in front by the pericardium. The large left lobe of the lung is attached by a membrane along its dorsal border to the esophagus, or to the membrane inclosing the pulmonary lobe mentioned above. 
Make a second longitudinal incision in the thoracic wall seven or eight millimeters to the right of the sternum. Separate the median strip, containing the sternum, from the diaphragm and turn the strip forward. The right lung will be exposed. Observe that the dorsal edge of the extreme posterior lobe on the right side is attached by a mesentery to the esophagus, which, in turn, is similarly suspended from the dorsal wall of the thoracic cavity.

Observe, also, the thymus gland anterior to the heart. This gland has no duct. Its secretion enters the blood. It is therefore an endocrine gland, or gland of internal secretion.

The veins of mammals show considerable variation. Fluctuations from the relations described in this text should be noted. While dissecting the veins, care should be taken to avoid injuring the arteries.

Venous blood from the regions of the body anterior to the heart drains into the right and the left superior vena cava (precaval veins), which enter the right atrium of the heart. Trace one of the superior venae cavae cephalad and note that it is formed by the confluence of the subclavian. and internal jugular veins. The right and left internal mammary veins pass from the ventral thoracic wall, each one parallel to and near the corresponding internal mammary artery, to the precaval vein of the same side. Both mammary arteries and veins will be seen in the median strip which has been reflected forward. The azygous vein empties into the left precava near its union with the heart. Follow the azygous dorsally at the left of the aorta, thence caudally parallel to the aorta, noting its tributaries. Is there a corresponding branch of the right precaval vein? Trace the internal jugular vein anteriorly to the thyroid gland.

The external jugular and cephalic veins unite near the 
middle of the clavicle to form the subclavian. The subclavian, coursing caudally, receives the blood from the anterior jugular vein, which enters the subclavian just median to the entrance of the external jugular.

Trace the external jugular vein anteriorly to its origin near the occipital region of the head. It receives blood, near its middle point, from the superficial muscles and skin of the occipital region through the posterior external jugular vein.

Cephalad to its union with the posterior external jugular, the external jugular is joined by the anterior facial vein. Trace this vein and its tributaries along the ventral and lateral regions of the head and identify them from the following description. The supraorbital vein, arising on the dorsal side of the head where it joins the superficial temporal (to be described), courses anteriorly and unites with the nasal vein at the base of the nose to form the angular vein. This runs ventrally, unites with the superior labial, and forms the anterior facial. The latter receives the inferior labial vein, continues ventrally, then caudally a short distance along the ventro-median border of the masseter muscle, and finally to its junction with the external jugular.

Carefully dissect the remaining tributaries of the external. jugular vein on the lateral side of the face, neck, and lower jaw. Identify these vessels from the following description. The superficial temporal vein, arising in the supraorbital region, passes ventrally posterior to the eye, receiving the transverse facial, which courses caudally near the zygomatic arch. Crossing the posterior root of the zygomatic arch, the superficial temporal runs posteriorly, is joined by the anterior auricular from the base of the external ear, then unites with the internal maxillary vein (described below) to form the posterior facial. The pos- 
terior facial runs through the parotid gland, and is superficial to the carotid artery. The confluence of the posterior auricular vein and the posterior facial forms the external jugular. The posterior auricular arises behind the external ear.

The internal maxillary will be found superficially on the median surface of the angle of the jaw. Here it curves laterally to join the superficial temporal, thus forming the posterior facial vein.

Exercise $X I V$. Make a labeled sketch of the veins anterior to the heart. This will be combined later (Exercise XXV) with a similar sketch of the veins posterior to the heart.

\section{ARTERIES ANTERIOR TO THE HEART}

The arterial blood leaves the left ventricle of the neart through the aorta. This turns dorsally and to the left, as the aortic arch, and runs caudally through the thoracic and abdominal cavities near the ventral surface of the spinal column. The thoracic and abdominal sections of the aorta are called the thoracic and abdominal aorta, respectively. The aortic arch of mammals is supposed to be homologous to the left fourth aortic arch of lower vertebrates. The branches of the aortic arch in the rat carry blood to the head, neck, fore limbs, and thoracic wall. Named in order from right to left, these branches are the innominate, left common carotid and left subclavian arteries.

The left subclavian artery runs cephalad from the aortic arch, carrying blood to the vessels described below.

Left internal mammary artery. Its origin is the left subclavian artery. It sends branches to the thymus gland, pericardium, and lung. On the inner surface of the ventral thoracic wall it turns medially to the side of the sternum and runs caudally, parallel to the internal mammary 
vein, giving off branches to the internal intercostal muscles. Trace it posteriorly along the dorsal surface of the rectus abdominis muscle, to which it sends branches. Several branches perforate the intercostal muscles and supply the pectoral and rectus abdominis muscles. Find the right internal mammary artery. Its branches and course are substantially the same as for the left internal mammary.

The vertebral artery upon leaving the subclavian passes cephalad about half a centimeter and enters the vertebrarterial canal at the sixth cervical vertebra. This canal consists of the transverse foramina of the cervical vertebrae. Running forward through this canal, the artery sends off branches between the vertebrae. It traverses the transverse foramen of the atlas, gives off a branch through the large oval foramen on the dorsal side of this vertebra, passes through the atlantal foramen, and enters the cranial cavity by way of the foramen magnum.

Thyro-cervical trunk. It leaves the subclavian artery medial to the first rib and passes anterolaterally to a position dorsal to the proximal end of the clavicle, where it divides into several branches. These branches supply glands on the surface of the neck, and muscles of the neck region.

Costo-cervical trunk. This vessel leaves the subclavian artery at the same level as the internal mammary, courses laterally anterior to the first rib, then sends branches to the lateral muscles of the thorax and deeper muscles of the neck.

The axillary artery is the continuation of the subclavian lateral to the first rib. Its branches are as follows.

(1) Lateral thoracic artery. It proceeds caudally from the axillary artery along the medial surface of the cutaneous maximus muscle.

(2) Subscapular artery. It arises from the axillary artery and divides into branches which supply muscles in the upper arm and thorax. 
(3) Deep artery of the arm. Leaving the distal end of the axillary artery, it sends branches to muscles of the upper arm (triceps), then proceeds distally along a spiral course, and finally sends branches down the anterior and lateral surfaces of the fore arm.

(4) The brachial artery, the continuation of the axillary, passes through the arm pit region, thence down the medial surface of the upper arm in company with the large nerves in this part of the arm. It lies throughout its length close to the posterior edge of the biceps brachii muscle. The artery provides branches for the muscles of the elbow region, but the main trunk passes down the forearm.

The second large arterial trunk leaving the aortic arch is the left common carotid artery. It originates from the aortic arch between the innominate artery and the origin of the left subclavian, and passes forward lateral to the trachea as far as the anterior end of the neck, where it splits into the external and internal carotid arteries.

The internal carotid artery proceeds anterodorsally from its origin and divides into two branches immediately posterior to the tympanic bulla. The dorsal branch of the two enters the tympanic bulla through the posterior lacerated foramen, which is situated on the median surface of the bulla immediately in front of the jugular process. The ventral branch enters the cranium by way of the carotid foramen.

The external carotid artery gives off the following branches.

(1) The occipital artery courses anterodorsally, from its origin immediately anterior to the internal carotid artery, passes around the median surface of the jugular process, thence dorsally to the dorsal musculature of the neck.

(2) The superior thyroid artery runs ventrally from its 
origin cephalad to the occipital artery, then posteriorly, sending branches to the thyroid gland, and one small branch to the larynx.

(3) The lingual artery leaves the external carotid anterior to the superior thyroid artery, enters the posterior region of the tongue, and follows a sinuous course nearly to the tip in the ventral part of that organ.

(4) The external maxillary or facial artery leaves the external carotid a short distance anterior to the lingual artery, and passes anteroventrally along the medial surface of the masseter muscle. Anteriorly it occupies the groove between the masseter and digastric muscles. It bifurcates about half a centimeter back of the angle between the upper and lower lips. The dorsal ramus supplies the snout and lateral wall of the mouth. The ventral ramus supplies the lower lip. This artery sends vessels to the lymph and salivary glands of the neck region, to the masseter muscle, the ventral musculature of the lower jaw, and the floor of the posterior region of the buccal cavity.

(5) Posterior auricular artery. The external carotid artery turns abruptly dorsally immediately after giving off the external maxillary. It turns anteriorly again ventrolateral to the tympanic bulla. The posterior auricular artery arises at the latter turn. It courses dorsally along the posterior surface of the external auditory meatus to the pinna of the ear, to which it sends branches. It also supplies the muscles adjoining the pinna. Trace the terminal branches of the external carotid.

The innominate artery is the first arterial trunk leaving the aortic arch. A short distance from its origin the innominate divides into the right common carotid and the right subclavian arteries. The subclavian passes anterolaterally to the anterior surface of the first rib, where, in company with the nerves of the brachial plexus, it leaves 
the thoracic cavity and becomes the right axillary artery.

The right internal mammary artery comes off from the posterior surface of the subclavian just median to the first rib. Its course is described in connection with the branches of the left subclavian.

The branches of the right axillary artery closely resemble those of the left. Verify this by a dissection of the vessels of the right arm.

Exercise $X V$. Sketch and label the arteries anterior to the heart. This drawing will be combined later (Exercise XXVI) with a similar sketch of the arteries posterior to the heart.

\section{THE HEART}

Study the attachments of the pericardium, the transparent membrane which surrounds the heart. If the thorax has been opened with sufficient care the pericardium will be unruptured. Insert a blowpipe through a small incision in the pericardium and inflate it with air. The pericardial cavity, the space between the pericardium and heart, is a part of the body cavity or coelom. The two other components of the coelom are the thoracic and $a b$ dominal cavities.

Remove the pericardium and study the heart in position. Note the attachments of the aortic arch, pulmonary arteries and veins, the superior venae cavae, and the inferior vena cava. The heart contains four chambers-two anterior atria and two posterior ventricles. The atrial and ventricular portions of the organ may be identified easily in a preserved animal. The atria are very dark in color because they contain masses of clotted blood, while the ventricles are decidedly lighter. The coronary sulcus is the deep furrow on the heart's surface which separates the atria from the ventricles. The right and left auricles (au- 
ricular appendices) are the ventral extensions of the right and left atria, respectively, which extend ventrally on each side of the pulmonary artery. Notice on the surface of the heart the injected coronary artery, which carries blood to the tissues of the heart, and the coronary veins, which drain the venous blood back into the general circulation.

The heart is a muscular pump which propels the blood throughout the body. Its complete failure to function means almost instant death. Venous blood returning from the capillaries of the muscles, brain, digestive organs, kidneys, etc. of the body enters the right atrium through the superior and inferior venae cavae. Contraction of the right atrium forces the blood into the right ventricle. The two atria contract simultaneously, but their contraction alternates with the simultaneous contraction (systole) of the ventricles. When the right ventricle is full it drives the blood through the pulmonary artery to the lungs, then relaxes (diastole) to receive more blood from the atrium. The excess of carbon dioxide carried by the blood is eliminated in the lung capillaries into the air contained in the minute air sacs (alveoli) of the lung. At the same time oxygen from the alveolar air penetrates the walls of the air saes and capillaries and unites chemically with the hemoglobin, or red coloring matter of the blood. The blood then traverses the pulmonary veins to the left atrium of the heart, thence to the left ventricle, and finally out through the aorta to the tissues of the body. The internal mechanism of the heart may now be elucidated by an examination of the dissected organ.

Insert one point of the scissors into the severed end of the pulmonary artery, carefully slit it lengthwise, continuing the cut along the lateral wall of the right ventricle. Bend back the cut walls and carefully wash out the coagu- 
lated blood. Observe the shape of the right ventricular cavity. It communicates with the pulmonary artery through the pulmonary orifice, which is surrounded by the three pocket-like segments of the pulmonary valve. Locate these valves and determine how they function. The right atrioventricular, or tricuspid, orifice is the aperture through which blood enters the right ventricle from the right atrium. It is guarded by the tricuspid valve. The inner surface of the ventricle bears muscular protuberances (trabeculae carneae), some of which (the papillary muscles) are attached to the tricuspid valves by slender strands, the chordae tendineae. When the ventricle contracts the blood starts to rush back into the atrium, but in so doing the tricuspid valve is thrust across the aperture by the blood stream. The edges of the valve would be forced up into the atrium were it not for the chordae tendineae and the papillary museles, which hold the flaps athwart the opening. Thus blood having once entered the right ventricle is unable to retreat into the atrium when the ventricle contracts, but must find its exit through the pulmonary artery. Insert the scissors' point into the severed inferior vena cava and open the right atrium by a cut extending forward to the right superior vena cava along the anterior surface of the atrium. Locate the openings of the superior and inferior venae cavae, and the atrioventricular aperture. Find the membranous valves near the entrance of the superior vena cava.

Slit the ventral wall of the left ventricle lengthwise by inserting one point of the scissors into the cut end of the aorta. Extend the incision to the apex of the heart. Try not to injure the aortic valve whose semilunar segments surround the opening of the ventricle into the aorta. The muscular wall of the left ventricle is considerably thicker than the wall of the right, for more pressure is required 
to send blood throughout the body than through the pulmonary circulation. Observe the trabeculae carneae on the inner surface of the left ventricle's wall. The aortic orifice, surrounded by the aortic valve, is the opening into the aorta. Part of the valve may have been torn in opening the ventricle. The mitral, or bicuspid valve surrounds the mitral orifice, through which blood passes from the left atrium to the left ventricle. Note the chordae tendineae extending from this valve also to the ventricular wall. The ventricular septum is the muscular partition between the cavities of the right and left ventricles. Open the left atrium, wash out the coagulated blood, and find the orifices of the pulmonary veins. How many openings are there? View the partition between the atria (the atrial septum) by strong transmitted light. The fossa ovalis is the translucent area which will be seen in this septum. Ask the instructor to explain its significance.

Exercise $X V I$. Make a diagrammatic sketch of the internal anatomy of the heart.

The arteries and veins posterior to the heart will be studied after the examination of the respiratory, digestive, and urinogenital systems. 


\section{THE RESPIRATORY SYSTEM}

The thoracic eavity of mammals is lined with a thin membrane, the pleura, in the form of two pleural sacs, one on either side of the median plane. The costal pleura covers the body wall, the diaphragmatic pleura the anterior surface of the diaphragm, while the pulmonary pleura is reflected over the outer surfaces of the lungs. The two pleural sacs meet in the median plane to form the mediastinal septum. The smooth surfaces of the pleura reduce the friction between the organs of the thorax.

The heart has already been removed. Clear away the muscle on the ventral side of the neck, exposing the trachea (or windpipe) and esophagus. The larynx, to be described later, is at the anterior end of the trachea. The thyroid gland is an $\mathrm{H}$-shaped gland of internal secretion lying on the trachea just back of the larynx. The isthmus, which corresponds to the transverse bar of the $\mathrm{H}$, runs across the ventral surface of the esophagus, joining the two lateral lobes of the gland. Throughout its length the trachea is in contact with the esophagus. The latter is dorsal to the larynx, but gradually swerves to the left until it passes into the thorax on the left side of the trachea. The heart and the vessels connected with it are ventral to both esophagus and trachea. The trachea bifurcates posteriorly, forming the two primary bronchi. Each bronchus leads to a lung. Observe the cartilaginous rings imbedded in the walls of the trachea and bronchi. They keep the lumen open for the free passage of air. Explain why the dorsal wall of the trachea is more flexible than the ventral. 
The left lung has but one lobe, the right has four. The lobe of the left lung is larger than any of the lobes of the right. Of the lobes of the right lung, three are in a row on the right side of the thorax. Each of these has a convex lateral and a concave median surface. The fourth, and hindmost, lobe of the right lung is approximately pyramidal in shape. The concave base of the pyramid lies against the diaphragm, the apex is directed toward the heart. It lies for the most part at the left of the median plane, and may therefore be mistaken for a lobe of the left lung if its connection with the right bronchus is not disclosed. It is inclosed in the membranous sac previously mentioned.

Exercise XVII. Outline the ventral view of that part of the dissected animal anterior to the diaphragm, and into this outline draw the pleural cavity, lungs, esophagus, trachea, thyroid gland, and larynx.

Trace the left primary bronchus into the left lung. Note how it divides into the secondary bronchi, these into the tertiary bronchi, etc. Follow the subdivisions of the right primary bronchus into the lobes of the right lung.

The volume of the thoracic cavity is increased by the periodic contraction of the muscles of the diaphragm and thoracic wall. Atmospheric pressure then forces air into the lungs through the nasal passages, trachea, and bronchi.

Remove the larynx. In doing so injure the pharynx as little as possible. The epiglottis is the flap attached to the anteroventral border of the larynx. When food is being swallowed the epiglottis folds back over the entrance into the larynx, thus preventing the passage of food into the trachea. The vocal cords are the pair of dorsoventral folds in the larynx. The glottis is the slit between them leading to the trachea. Dissect away the shreds of muscle tissue adhering to the larynx, exposing the cartilages in 
its wall-the thyroid, cricoid, and arytenoid cartilages. This may be done more easily under a dissecting microscope. The thyroid cartilage is a band extending around the anteroventral and lateral regions of the larynx. Each lateral extremity gives off an anterior and posterior horn, the latter joining the cricoid cartilage. The ventral portion of the cartilage bears a median notch on the anterior border, and is bound to the cricoid cartilage by the cricothyroid ligament. The cricoid cartilage has the shape of a signet ring, completely encircling the air passage. It is narrow ventrally, but expands dorsally into a hexagonal plate whose dorsal surface is concave. It is firmly united to the trachea by connective tissue. The arytenoids are a pair of small cartilages articulating with the anterior border of the dorsal plate of the cricoid. Each attaches to the dorsal end of a vocal cord.

Exercise XVIII. Draw and label the larynx. 


\section{THE VASCULAR SYSTEM (Continued)}

\section{THE HEPATIC. PORTAL SYSTEM}

Prepare now to study the contents of the abdominal cavity, that part of the coelom which lies posterior to the diaphragm. Slit the abdominal wall in the sagittal plane from the diaphragm posteriorly nearly to the external genital organs, which lie between the hind legs. Do not injure either the external or internal genital organs. Make an anterior and a posterior cut at right angles to this longitudinal incision, reflect the lateral flaps, exposing the digestive and reproductive systems lying in the abdominal cavity. Examine the mesenteries supporting the digestive organs, and observe their veins.

The portal system comprises the veins which carry to the liver the blood from the capillaries of the intestines, stomach, pancreas, and spleen. All the tributaries of this system converge to the portal vein which goes into the liver immediately ventral to the entrance of the inferior vena cava into that organ. Trace the ramifications of the portal system throughout the mesenteries of the stomach and intestines. Just before it enters the liver the portal vein receives the pancreatico-duodenal vein from the duodenum and pancreas, and the gastro-epiploic vein from the pancreas and greater curvature of the stomach. These two vessels unite and enter the portal vein by a common trunk. The portal vein is formed by the confluence of the gastrosplenic and superior mesenteric veins. The gastro-splenic is formed by the union of branches from the spleen, pancreas, and lesser curvature of the stomach. The superior 
mesenteric vein drains the ascending colon, caecum, and small intestine. It receives the inferior mesenteric vein from the descending colon.

Exercise $X I X$. Make a diagrammatic drawing of the hepatic portal system. 


\section{THE DIGESTIVE SYSTEM}

The digestive system consists of the mouth cavity, pharynx, esophagus, stomach, small and large intestines, salivary glands, liver and pancreas.

The mouth opening is triangular. It is located on the anteroventral surface of the head some distance back from the tip of the snout. The lower lip conceals the greater part of the two long lower incisor teeth. Externally it is hairy; internally it is covered with smooth mucous membrane. A fleshy ridge on its inner surface fits into the space between the incisor teeth. This ridge joins ventrally a short vertical septum, the frenulum, which passes between the incisor teeth, connecting the lip with the mandible. From the angle of the mouth a lobe of integument, covered with hair, turns upward along the inner surface of the cheek.

The lateral halves of the upper lip meet in front at an acute angle pointed toward the nasal septum. The apex of the angle is connected with the septum by a groove. The upper lip is therefore cleft, exposing the incisor teeth of the upper jaw. A frenulum is lacking. The edge of each upper lip immediately behind the incisor teeth is turned inward, forming a lobe whose lower hairy surface touches the dorsal surface of the tongue. This lobe is hairless dorsally, and is in contact here with the roof of the mouth. The lip lobes, tongue, and a fleshy tubercle on the middorsal surface of the mouth's roof just behind the lobes, are all in contact with one another when the jaw is closed, practically separating the mouth opening from the mouth cavity. 
The teeth have been described in connection with the bones of the cranium. There are two long pairs of chisellike incisor teeth, one pair in the upper and one pair in the lower jaw. The lower pair protrudes farther into the mouth eavity than the upper. The upper incisors incline slightly backward. The lower extend forward from the anterior end of the under jaw, curving upward to their points which lie a little behind the tips of the upper incisors when the jaw is closed. Immediately behind the incisor teeth is the toothless region, the diastema. The three upper and three lower molar teeth for grinding the food torn loose by the incisors, are back of the disastema.

The mouth cavity comprises two parts, the vestibule lying between the teeth on the one hand and the lips and cheeks on the other, and the mouth cavity proper. The vestibule is composed of two completely separated parts-the incisor and the molar. The former lies between the incisor teeth and the lips. On the lower jaw it is well developed, but on the upper is almost completely lacking on account of the cleft in the upper lip. The molar region of the vestibule is a narrow region between the molar teeth and the cheek. The discontinuity of the two parts of the vestibule is due to the absence of teeth in the diastema. The folds of the upper and lower lips and cheek are the only structures on the lateral side of the mouth in the diastema region. The mouth eavity proper is widest in the region of the molar teeth. It decreases in width anteriorly and between the tongue and soft palate extends back as a narrowed passage opening into the pharynx through the isthmus faucium at the posterior end of the soft palate.

The roof of the mouth comprises two regions, the hard palate supported by the palatine processes of the premaxillary, maxillary, and palatine bones, and the soft palate, which consists of a boneless, flexible wall extending back- 
ward from the hard palate. The surface of the soft palate bears small papillae. The palate is widest at the posterior part of the molar tooth region, decreasing in width forward to the inturned lobes of the upper lips, and backward to the pharynx. A membranous ridge, the palatine arch (pillar of the fauces), extends ventrally from the posterior end of the soft palate on each side of the isthmus faucium. The hard palate bears eight transverse ridges, the most anterior of which is ventral to the prepalatine foramina. The three anterior ridges are the largest and lie in front of the molar teeth. The other five ridges are within and behind the molar region. These five may assume approximately the form of a letter $w$, with the base of the letter forward, or the form of a bow, or of an obtuse angle whose anteriorly directed apex lies in the mid-dorsal region of the palate. Each of the five ridges bears a row of short spines throughout its length. Other denticulated ridges, which do not reach the median line of the hard palate, may also be present. At the posterior end of the hard palate is a triangular area bearing spines.

Carefully disarticulate the lower jaw. The tongue is an elongated muscular organ extending from the pharynx forward to the incisor teeth. It fits snugly into the floor of the mouth between the molar teeth. Anterior to the molars it is unattached to the mouth floor. The vertical frenulum which in some animals connects this anterior free region of the tongue with the mouth floor is absent. A median dorsal furrow extends seven or eight millimeters back from the tip. The tongue is attached to the floor of the mouth from the anterior molar teeth caudad. The proximal one-sixth of the organ is attached on both sides also, so that it alone forms the floor at the back of the mouth. The tongue unites with the hyoid bone a short distance in front of the epiglottis. 
Papillae cover the dorsal surface of the anterior threequarters of the tongue, the tip, and dorsal portions of the lateral surfaces. They are entirely lacking on the posterior quarter of the upper surface, ventral portions of the lateral surfaces, and the under side of the free anterior end. The filiform papillae are slender pointed structures with their tips generally directed backward. On the anterior half of the dorsal surface these papillae are rather conspicuous when seen under the dissecting microscope. In a triangular area about half way between the anterior and posterior ends of the tongue the filiform papillae are larger than elsewhere, conical and erect. The filiform papillae back of this area are so numerous and slender that here the tongue has a velvety appearance under the dissecting microscope. A few, low, cylindrical fungiform papillae are seattered over the anterior half of the dorsal surface, chiefly toward the tip.

There is no organized tonsil. This organ is represented merely by scattered follicular openings on the longitudinally folded side walls of the narrow faucial canal.

Exercise $X X$. Sketch a dorsal view of the tongue.

The soft palate forms the ventral floor of the nasopharynx (pars nasalis). This is a relatively large cavity which opens anteriorly through the single posterior naris into the nasal cavity. Toward its posterior end the nasopharynx curves downward and opens into the pharynx proper. The lateral walls are supported by the sphenoid processes of the palatine bone and the median pterygoid processes of the alisphenoid, while the basisphenoid and presphenoid bones support the roof. The auditory (Eustachian) tubes from the middle ears open into the nasopharynx about half a centimeter from the posterior border of the soft palate. The opening of each tube is a longitudinal slit near the angle between the lateral and dorsal 
walls, on the same side of the nasopharynx as the ear with which the tube is connected.

The pharynx proper lies back of the mouth eavity. It has four openings. Anterodorsally it communicates with the nasopharynx, anteroventrally with the mouth cavity, through the isthmus faucium, posteriorly with the esophagus, and ventrally with the larynx and trachea through the glottis, the entrance to the larynx. The food coming from the mouth passes through the pharynx to the esophagus. The air entering and leaving the lungs also traverses the pharynx. It is therefore a part both of the digestive and respiratory tracts. During respiration the free end of the epiglottis is raised to allow the passage of air to and from the larynx. The epiglottis bends backward and covers the glottis when food is swallowed, preventing the entrance of food into the trachea. A u-shaped, fleshy ridge on the dorsal wall of the pharynx, together with the posterior edge of the soft palate, form an ovoid opening into the nasopharynx which incloses the epiglottis and the glottis when the roof of the pharynx is depressed. Probably this arrangement permits breathing to continue, without drawing particles into the respiratory passages, while the animal is gnawing materials which it does not swallow. A recess of considerable size lies lateral to this semicircular ridge.

The esophagus is the tube which conveys food from the pharynx to the stomach. From its position anteriorly on the dorsal side of the larynx, it follows the dorsosinistral surface of the trachea to the level of the first rib, where it rests against the left surface of the trachea. Entering the thorax, the esophagus runs backward, dorsal to the aortic arch and primary bronchus, to the diaphragm, which it pierces. Posterior to the liver, in the abdominal cavity, the esophagus enters the stomach. 
Open the abdominal cavity by a median incision from the diaphragm to the pelvis.

The stomach lies on the left side in the abdominal eavity, in contact with the concave posterior side of the liver. It resembles a half of a doughnut in shape. The long axis forms approximately a right angle with the long axis of the body. The greater curvature which corresponds to the outer edge of the doughnut, is ventral. The lesser curvature, analogous to the rim of the doughnut's hole, is dorsal. The esophagus enters the stomach on its dorsal side, through the cardiac orifice, or cardia, near the center of the lesser curvature. The esophagus is closer to the right half of the lesser curvature than to the left, thus entering the stomach obliquely. External inspection of a full stomach reveals two distinct regions. The wall of somewhat more than the left half, the cardiac sac, is flexible, thin, and in a preserved specimen sufficiently transparent to permit the food it contains to be seen from the outside. The wall of the right region of the stomach, on the other hand, is opaque and relatively firm. This part decreases in size dorsally and communicates with the small intestine through the pylorus. The inner surface of the stomach comprises two areas corresponding to the two regions seen from the outside. These may be seen to good advantage by opening the distended organ with an incision extending throughout the length of the greater curvature. The inner surface of the cardiac sac at the left is hard, smooth, and glossy. The wall is tough. If the stomach was distended with food when the animal died, the wall is slightly transparent, the transparency increasing as the tissue dries. In the region at the right the inner surface is yellowish in color, opaque, brittle in a preserved animal, and more or less prominently folded, especially near the pylorus and on the greater curvature. The two re- 
gions are sharply separated by the horny boundary fold, which extends ventrodextrad, on the anterior and posterior surfaces, from the vicinity of the cardia. The wall of the cardiac sac is opaque in an empty stomach, and its inner surface is extensively folded. The esophagus opens into the cardiac sac, for it lies at the base of the tongue-like dextral extension of the sac's horny lining. The part of the boundary fold bordering the right end of this extension is highly sinuous.

Food passes to the small intestine through the pylorus, at the upper right hand extremity of the stomach. The pylorus contains a ring of muscle whose contraction closes the digestive tube, shutting off communication between the stomach and intestine. It regulates in this manner the passage of food from the stomach to intestine. The position of the pylorus is indicated externally by a groove around the alimentary canal. Internally the high ridges in the glandular part of the stomach are replaced at, or slightly to the right of, the pylorus by the velvety surface of the small intestine.

The stomach wall of the mouse (and rat also) are said to show the following structures. There are two muscle layers, a thick circular and a thinner longitudinal layer. The cardiac sac and boundary fold are lined internally by the statum corneum, or horny layer of epithelial cells. There are three zones in the glandular tissue at the right of the boundary fold. The cardial glands surround the tongue-like extension of the horny epithelium at the right of the cardia, and extend ventrally along the anterior and posterior walls. The rennet glands are on the ventral wall at the right of the boundary fold. The pyloric gland region lies between the pylorus, and the cardial and rennet glands. The glands of the mammalian stomach secrete the gastric juice which initiates the digestion of protein substances in 
the food. The cardiac sac of the rodent, with its horny lining, is thought to be a storehouse for holding chewed food pending gastric digestion. It has been suggested that the dangers involved in feeding have led Rodents to develop this thin-walled sac in which quickly procured food may be stored.

The intestine is the part of the alimentary canal in which the digestion and absorption of food is completed. It is an extensively coiled tube occupying a large part of the abdominal cavity. It is physiologically and morphologically divisible into two parts, the small and the large intestine. The discussion of the mesenterial supports will be deferred until after the description of the alimentary canal itself. The length of the small intestine may be about 70 centimeters, more than three times the length of the animal from the tip of the snout to the base of the tail. The large intestine, including caecum and rectum, is about 20 centimeters long. The small intestine comprises the duodenum, jejunum, and ileum.

The duodenum lies on the right side of the abdominal cavity. It is approximately $u$-shaped, and is therefore composed of three parts-a descending, a transverse, and an ascending limb. The first joins the stomach at the pylorus. From this attachment it turns posterodextrad in a broad curve, and runs backward about four centimeters near the right abdominal wall. The transverse duodenum is the sharp short curve at the posterior end of the descending limb, connecting the latter with the ascending limb. The latter passes forward along the right side of the colon, and is connected by a mesentery with the distal edge of the mesocolon. In a preserved specimen the duodenum is pinkish or slightly grayish in color. The gross structure of the internal surface may be observed to good advantage with a dissecting microscope if a fresh 
duodenum be slit lengthwise, spread out, thoroughly cleaned, and hardened with formalin. The mucous membrane is folded into very closely packed, relatively short, flat, transverse ridges. The longer ridges follow a zig-zag course and their distal edges are lobed. The ridges probably facilitate digestion by increasing the secretory and absorptive surface of the intestine.

The jejunum follows the duodenum. It constitutes in man two-fifths of the small intestine, exclusive of the duodenum. Its inner surface, like that of the duodenum, is thickly covered with short, flat, transverse ridges.

The ileum is not sharply separated from the jejunum in man. It connects the jejunum and the colon. In the rat it is characterized by its dark color, due to the color of the contained feces. The mucous membrane of the ileum is also thrown into numerous closely packed transverse ridges.

The contents of the ileum pass through the ileocolic valve into a small chamber which communicates by wide openings both with the colon and the caecum. The latter is a sac measuring about two and one-half centimeters on its longest axis. It varies in shape, sometimes resembling an interrogation mark, or assuming the form of a short spiral. Thus it has a greater, or outer, and a lesser, or inner, curvature. At one end it opens into the intestines. A mesentery connects the lesser curvature with the ileum. The caecum contains a mass of dark fecal matter. When this is removed it will be seen that the inner surface presents smooth areas of considerable extent, but bears folds also. These folds are transverse along the inner curvature, but near the proximal end they radiate, in general, from the opening of the caecum.

From the caecum and ileum the feces enter the ascending colon. This follows an irregular route forward, ventral to the duodenum but dorsal to loops of the jejunum 
and ileum, to the region of the stomach. Here the colon (transverse colon) circles dorsally and to the left as far as the sagittal plane of the body. The descending colon follows approximately the sagittal plane of the body back to the rectum. The ascending limb of the duodenum lies at the right of the descending colon, and both are close to the dorsal surface of the abdominal cavity. The rectum is the continuation of the colon through the pelvis. It terminates posteriorly at the anus, where the feces are expelled. There is no sharp boundary between colon and rectum. The dark fecal matter in the colon forms pellets shaped like cotton seeds. Wherever these masses occur the inner surface of the colon is smooth. Elsewhere the lumen is practically devoid of feces and the surface is thrown into prominent folds, the colic ridges. The absence of ridges and the greater diameter of the colon where the fecal pellets occur shows that at least one purpose of the ridges is to permit distension of the mucous membrane of the colon without undue strain upon it.

The liver is a firm, bulky, dark red organ lying in the anterior region of the abdominal cavity. Its convex, cranial surface rests against the concave posterior face of the diaphragm. Ventrally it rests upon the abdominal wall. Its caudal surface is concave and is in contact with the stomach and intestines. The organ is deeply cleft into several very distinct lobes and lobules.

The median lobe occupies a median position in front of the other lobes of the liver. A longitudinal fissure near the sagittal plane of the body partly divides this into two lateral lobules, approximately equal in size, sometimes referred to as the right and left central lobes. This fissure extends from the thin posterior edge of the lobe nearly to the ventral border of the diaphragm, where it receives the round ligament. Dorsal to this point the two lobules are 
united anteriorly, and are in contact with the diaphragm. Posteriorly, the fissure extends upward, sometimes reaching the region of the inferior vena cava. The right lobule passes upward to the right of this vein, the left lobule to the left. The median lobe is fastened in this region to the vena eava. Very little, if any, hepatic glandular tissue connecting this lobe with the rest of the liver, is visible in a gross dissection.

The left lateral lobe is immediately behind and at the left of the median lobe of the liver. It attaches to the other lobes of the liver only at its dorsomedial angle, and here merely by its ducts, blood vessels, and connective tissue. The anterior surface is strongly convex, the posterior surface is concave and rests against the stomach and intestines. The lobe is thick near the center, tapering to a thin edge peripherally. The right side pushes in between the median and right lateral lobes.

The right lateral lobe lies behind and at the right of the median lobe. A vertical transverse cleft divides it into two almost completely separated lobules, one anterior, the other posterior. A bridge of hepatic tissue crossing the dorsal side of the inferior vena cava connects the two lobules with one another and with the caudate lobe on the left side of the abdomen. The posterior lobule is frequently annexed to the caudate lobe by a strip of hepatic glandular tissue crossing the ventral surface also of the inferior vena cava. Both lobules attach to the right surface of the vena cava. Aside from the glandular bridges mentioned above, a gross dissection fails to reveal connections of hepatic tissue with the other lobes of the liver. The anterior lobule is thick near the center, thinning out toward the sharp peripheral edges. Its convex anterior surface fits into a concavity near the right border of the median lobe. The right lateral surface rests against the diaphragm. 
The caudal surface presents a ventral convexity and a dorsal concavity to the cranial surface of the posterior lobule. The concavity receives also the anterior surface of the right kidney and the accompanying adrenal gland. A ventral strip of the posterior surface is presented to the descending limb of the duodenum. The posterior lobule is approximately pyramidal. The base of the pyramid fastens to the right side of the inferior vena eava. The triangular surface facing the anterior lobule is slightly concave medially, decidedly convex laterally, so that the apex of the pyramid points backward. The renal impression is the concave triangular dorsal surface which receives the ventral side of the right kidney. A spur of the lobule runs dorsal in front of the kidney. Occasionally the posterior lobule is more or less divided into two secondary lobules.

The caudate lobe (Spigelian lobe) comprises two distinct semicircular lobules, the anterior and the posterior lobules. These unite mediad with each other and with the left side of the inferior vena cava, but are separated laterally. As previously mentioned, the caudate lobe is annexed to the right lateral lobe dorsal, and sometimes ventral, to the inferior vena cava. These lobules fit neatly into the lesser curvature, and adjacent surfaces, of the stomach. The anterior lobule is in front of this organ, the posterior behind it, lying in the lesser peritoneal cavity. The esophagus fits into a groove, the esophageal impression, on the caudal surface of the anterior lobule.

The liver and diaphragm are united by several membranous ligaments which radiate outward from the region where the inferior vena cava pierces the diaphragm. The falciform (or suspensory) ligament of the liver lies in the sagittal plane of the body. It connects the diaphragm ventral to the inferior vena cava with the anterior surface 
of the median lobe. The round ligament (ligamentum teres hepatis) is the ventral thickened border of the falciform ligament. It enters the dorsal end of the fissure in the median lobe. The left triangular ligament is a triangular sheet connecting the dorsal edge of the left lateral lobe with the diaphragm. It unites with the diaphragm along a line running from the vena cava to the left and to the dorsal margin of the diaphragm. The right triangular ligament is a comparatively broad sheet connecting the dorsal side of the right lateral lobe with the diaphragm.

The rat's liver possesses no gall bladder for storing the bile, the digestive secretion of the liver. The hepatic ducts convey the bile from the liver lobes to the bile duct (ductus choledochus) which then passes along the duodenohepatic omentum, ventral to the portal vein. The duct traverses the dorsal side of the pancreas and enters the mensenterial side of the duodenum about three centimeters from the pylorus. The liver receives arterial blood from the hepatic artery, and venous blood from the alimentary canal through the portal vein. Food substances absorbed from the alimentary canal are carried to the liver through this vein. Carbohydrates are stored there in the form of glycogen. Blood leaving the liver enters the inferior vena cava through the hepatic veins.

\section{MESENTERIES OF THE ALIMENTARY CANAL}

The digestive organs of the vertebrates are connected with one another and with the walls of the abdominal cavity by membranes. The membranes uniting the organs with the dorsal abdominal walls are called mesenteries. Of these the mesogastrium supports the stomach, the mesentery proper the intestine, and the mesocolon supports the colon. The alimentary canal in all vertebrates except 
the Cyclostomes is more or less convoluted, and the parts are held together by mesentery-like structures. The hepatogastric ligament ties the stomach to the liver, the gastrosplenic ligament connects stomach and spleen, the hepatoduodenal ligament unites duodenum and liver.

Though the mesenteries of the rat have doubtless evolved from a simpler arrangement, such as that found in the dogfish, they are relatively complex, and require careful study.

The mesogastrium of the rat is expanded into the form of a sac, the greater omentum, which projects backward from the stomach region. The rim of this sac unites with the stomach upon a line extending from the pylorus along the greater curvature of the stomach, around the left end and back to the esophagus on the lesser curvature. Dorsad the greater omentum unites with the body wall between the adrenal glands. The omental sac thus comprises two limbs, a dorsal one united anteriorly with the dorsal abdominal wall, and a ventral limb attached to the greater curvature of the stomach.

The spleen is suspended along its median surface to the left side of the omental sac. It lies parallel to the greater curvature of the stomach. The part of the great omentum connecting the spleen and stomach is the gastrosplenic or gastrolienal ligament. A part of the pancreas is lodged in the descending limb of the great omentum.

The descending colon lies in the sagittal plane of the body. It is held in this position throughout its length by the relatively narrow mesocolon, which joins the dorsal abdominal wall just beneath the inferior vena cava. The mesocolon terminates about three and one-half centimeters from the anus. Anteriorly it fastens on the left to the great omentum. The duodenocolic omentum connects the descending colon and the ascending limb of the duodenum. 
Its attachment extends throughout nearly the whole ascending limb of the duodenum. Its connection with the descending colon is in common with that of the mesocolon.

The mesoduodenum spans the gap between the ascending and descending limbs of the duodenum. It joins the dorsal abdominal wall at the anterior end of the duodenal loop, as described below.

At its anterior end the duodenum turns sharply ventrad to join the jejunum. The mesentery of the jejunum and ileum serves also for the ascending colon, and is therefore both mesentery of the small intestine and a part of the mesocolon. The central axis of the mesentery carries the blood vessels which bear blood to and away from the intestines. The jejunum and ileum are very much longer than the axis of the mesentery. Therefore the mesentery's edge attached to them is expanded into many convolutions. This arrangement gives great freedom for movement of the small intestines, so that the peristaltic action, which forces the food along the canal, is not hindered by the mesenterial attachments. If an anaesthetized animal is opened, the movements of the small intestines can be seen.

The ascending colon is about as long as the axial portion of the mesentery. Therefore this edge of the mesocolon is not thrown into folds. A short triangular mesentery passes between the caecum and the distal end of the ileum. The transverse colon is tied to the mesoduodenum by a short mesentery. The length of the ascending mesocolon, as compared with the relatively short mesenterial connections of the transverse and descending colons, leaves the ascending colon relatively free for movement. Proximally this complex of jejunal and ilial mesenteries and mesocolon, fuses with the anterior part of the mesoduodenum. The combined mesenteries then join the dorsal wall of the ab- 
domen between the kidneys and at the left of the inferior vena cava.

The pancreas secretes a digestive fluid, the pancreatic juice, which contains three enzymes, trypsin, steapsin, and amylopsin. The gastric juice of the stomach contains pepsin which reduces protein food substances to soluble peptones. These, in turn, the trypsin breaks down into amino acids, which are absorbed in the intestines. Steapsin decomposes fats into fatty acids and glycerin. Amylopsin reduces all digestible carbohydrates to glucose, which is absorbed and stored in the liver as glycogen.

The pancreas of the rat is irregular in shape and divided into many large and small lobes. Some of these lobes anastomose with each other. The pancreas is suspended in the descending limb of the great omentum, and throughout the mesoduodenum. It bends dorsally in the mesenterial junction of these membranes, and also sends a lobe to the pyloric region of the stomach. Its left end is dorsal to the spleen. Pancreatic tissue lies close against the mesenterial side of the duodenum throughout the duodenal loop.

The pancreatic juice enters the bile duct, as it crosses the pancreas, through several small ducts. The openings of these ducts into the bile duct may be seen if the latter is slit and its inner surface examined under the dissecting microscope. The bile duct conducts the pancreatic juice, with the bile, to the duodenum. These ducts are identified with difficulty unless a careful dissection be executed using a microscope.

Exercise $X X I$. Make an enlarged drawing of the opened abdominal eavity, showing as many as possible of the contained organs and mesenteries. 


\section{THE UROGENITAL SYSTEM}

The reproductive and excretory organs are closely associated in structure and function, and are therefore collectively termed the urogenital, or urinogenital, system. In dissecting the urogenital organs be careful not to cut the blood vessels, which will be studied later.

The two kidneys are the two principal excretory organs of the body. The renal arteries carry the blood to the kidneys, where urea, salts, excess water, etc. are removed from the blood, which then passes to the inferior vena eava through the renal veins. Each kidney is a bean-shaped organ, covered ventrally by peritoneum, and attached to the dorsal wall of the abdomen. The hilum, or depression where the renal blood vessels and ureter enter, is on the median surface. The dorsal surface is flattened, the ventral surface is convex. The anterior end of the right kidney fits into the concave surface of the right lateral lobe of the liver. The left kidney is displaced caudad, so that its hilum is slightly posterior to the level of the posterior end of the right kidney. This displacement is probably due to the presence of the stomach on the left side of the body. The ureter is the tubule which conveys the urine from the kidney to the urinary bladder. Find where it leaves the hilum of the kidney and trace it back to the bladder.

The suprarenal gland is a somewhat hemispherical body immediately anterior to each kidney. It lacks a duct. The secretion (adrenalin) known as an internal secretion, enters the blood, which carries it to those parts of the body where it performs its functions. 
Remove both kidneys from the body. With a sharp razor or scalpel divide one kidney into its dorsal and ventral halves, and bisect the other by a transverse cut passing through the hilum. The cut surfaces reveal the outer cortical and inner medullary regions of the kidney. Within the latter note the dorsoventrally flattened papilla which projects into the internal cavity, or sinus, of the kidney. The urine collects in the sinus and drains into the ureter through its funnel-shaped anterior end, the pelvis, which is located at the hilum of the kidney. Insert a fine bristle into the pelvis where it surrounds the tip of the papilla and by careful probing locate the lumen of the ureter.

Exercise $X X I I$. Draw the cut surfaces of the bisected kidneys.

\section{THE MALE UROGENITAL ORGANS}

The spermatozoa, or male sex cells, are produced in the two testes, which develop in the embryo near the attachment of the mesentery to the dorsal side of the abdominal cavity. In the lower vertebrates the testes remain throughout life near their embryonic position, but in most mammals they come to lie in an integumentary sac, the scrotum, ventral to the anus. This scrotal sac incloses two extensions of the coelom, each of which communicates in the embryo with the abdominal cavity through the inguinal canal. This canal marks the position of the scrotal evagination. The testes usually descend from the abdominal cavity, through the inguinal canals, into the scrotal sac, though in the whale and elephant they remain in the abdominal cavity. Such a condition (cryptorchism) occasionally occurs in man. The inguinal canal remains open in marsupials, bats, rodents (including the rat), insectivores, etc. The descent of the testes in these animals is temporary, and at the close of the breeding season the testes are withdrawn into the abdomen by the cremaster 
muscle. Rats dissected in the laboratory frequently show the testes more or less completely retracted into the abdomen.

The scrotum of the rat is a prominent swelling, about four centimeters long in a large male, lying on the ventral side of the body between the anus and penis. Like the rest of the integument it is covered with hair. A longitudinal groove on its ventral surface marks the position of the septum scroti, an internal partition which separates one testis from the other.

Carefully slit the scrotum ventrolaterally on one side throughout its entire length, using care to cut no deeper than the integument. Cautiously separate the integument, which is the scrotum proper, from the underlying layer of connective tissue. This connective tissue forms a sac which joins a similar sac surrounding the other testis to form a median partition, the septum scroti. Slit, the connective tissue sac lengthwise and determine the number of layers in it. A muscular sac will be observed immediately under the connective tissue. It may be traced forward to the ventral abdominal muscles. Microscopic examination of a piece of this muscle will show that it is two-layered and that the fibers are cross striated. The fibers of one layer cross those of the other nearly at right angles.

Each testis is an ovoid body about two centimeters long. It lies lengthwise of the scrotum. The epididymis is closely associated with the testis phylogenetically, structurally, and functionally. It comprises three parts. The enlarged anterior end, or caput epididymidis (head), curves around the anterior end of the testis, and is attached ventrally and mesially to it by a mesentery. The slender corpus epididymidis (body) passes along the dorsal side of the testis, connecting the caput epididymidis in front with the 
cauda epididymidis behind. The latter expands posteriorly and curves down around the posterior end of the testis. The ductus deferens is the conspicuous tube which passes forward from the median side of the cauda epididymidis, through the inguinal canal into the abdominal cavity.

The epididymis and ductus deferens are both attached to a mesentery which extends from the dorsal side of the testis to the dorsal wall of the scrotal cavity. Anteriorly this mesentery also incloses the blood vessels which carry blood to and away from the testis. Fat accumulates in considerable quantity in front of the epididymis and within ventral prolongations of the mesentery which extend through the inguinal canal into the abdominal cavity.

The mammalian scrotal cavity, like the abdominal cavity from which it is derived, is lined with peritoneum, the tunica vaginalis. The testis, like the intestine, is almost completely invested with peritoneum and is suspended in the scrotal cavity by the mesentery, which is covered on both sides by the peritoneal layer. The wall of the testis is a very tough, fibrous, transparent membrane, the tunica albuginea. This incloses a mass of convoluted seminiferous tubules, readily seen through the tunic. Slit the latter lengthwise of the testis and with a needle tease out some of the tubules, noting their convolutions. These tubules produce the spermatozoa.

The epididymis is covered by a tough transparent membrane similar to the tunica albuginea of the testis. Through the membrane may be seen tubular convolutions. The ductus deferens becomes coiled when it enters the cauda epididymidis. Verify this by a careful dissection.

In man the spermatozoa, produced by the epithelial lining of the seminiferous tubules, pass through efferent ducts, the ductuli efferentes testis, to the caput epididymidis, where they are collected into a single duct, the duct of the 
epididymis. The convolutions of this tube form the body and tail of the epididymis. The tube emerges from the cauda epididymidis, and as the ductus deferens conducts the sperm cells to the urethra. This arrangement doubtless obtains, in all essential details, in the rat also.

The epididymis of Amniotes is homologous to a part of the mesonephros of the adult Ichthyopsida. The mesonephros is a kidney and a sperm carrier in the latter group. The excretory function is retained by the mesonephros in the mammalian embryo, but in the development of the male the organ undergoes partial degeneration, so that in the adult only the sperm-carrying function is retained.

The ductus deferens of the rat, after entering the abdominal cavity through the inguinal canal, turns medianly, curves around the ventral surface of the ureter, and joins the urethra.

There are several accessory glandular structures in this region. The vesicular glands are a pair of conspicuous, warty structures at the posterior end of the abdominal cavity. The anterior end of each gland bends abruptly caudad, so that each gland, as a whole, somewhat resembles an interrogation point. The gland is hard and brittle in a preserved animal. Open it and remove some of the coagulated secretion. It breaks into fine particles when rubbed between the fingers. This secretion is produced by the wall of the gland, which is said to contain a strong mantle of smooth muscle. Find the duct and trace it caudad to its entrance into the anterior end of the urethra. These organs were formerly called seminal vesicles, but they contain no spermatozoa. It is said that the glands produce an alkaline secretion which is mixed with the sperms, upon whose movements the secretion probably exerts a favorable influence. It is claimed that extirpation of the glands reduces the animal's reproductive capacity. 
Note the elongated flattened gland lying against the concave surface of the vesicular gland. Find its duct and trace it to the anterior end of the urethra. Find also the pair of small glands (probably the ampullary glands), each of which encircles the ductus deferens near its entrance into the urethra.

The prostate gland comprises two regions. One attaches to the dorsal and lateral surfaces of the proximal end of the urethra, and to the dorsal side of the vesicular gland. The other region consists of two prominent lobes lying ventral to the urinary bladder, to which they are attached. The lobes are also fastened to the adjacent body wall. Dissect away the tough external tunic of connective tissue, and note that both parts of the gland are a mass of tubules. The prostatic secretion in man dilutes and lends bulk to the seminal fluid. It has been suggested that in rodents the secretion assists the locomotion of the sperm cells, and also nourishes them.

The urinary bladder is an oval sac attached to the dorsal surface of the ventral part of the prostate gland. The bladder narrows proximally to the neck, which joins the ductus deferentia to form the urethra. Each ureter, or urinary drainage tube of the kidney, joins the corresponding side of the bladder near the neck. Urine entering the bladder through the ureters, is stored there temporarily, then flows through the neck into the urethra, whicb conveys it to the outside. The urethra also carries the spermatic fluid during copulation.

The descent of the testis carries the ductus deferens ventral to the ureter. This accounts for the way these tubes loop around each other in the adult.

A mesentery in the sagittal plane connects the bladder and posterior part of the prostate gland with the ventral body wall. 
Divide the pelvic girdle along the symphysis pubis, remove the ventral part of this girdle, clear away the adjacent muscles, and expose the urethra. This runs back through the girdle ventral to the rectum. The urethra joins the penis at the posterior end of the pelvic girdle. At this place the two bulbo-urethral (Cowper's) glands pour their secretion into the urethra through a pair of long ducts. Each of these glands is ovoid in shape and about five millimeters long. It lies lateral to the rectum and just behind the posterior border of the ischium. It has been suggested that the secretion protects the spermatozoa against the harmful effects of traces of urine.

Dissect away on one side the tissues surrounding the penis. Note that it has the form of a figure 7 , with the angle anteroventral. Carefully insert one blade of the scissors into the genital orifice and slit the integument lengthwise of the body. Press aside the flaps of skin and note that the terminal section of the penis, the glans, lies loose in a chamber surrounded by the prepuce or foreskin. The surface of the glans is slightly rough. Its blunt free end points backward. The two preputial glands, one on either side of the glans penis, discharge their secretion near the posterior edge of the prepuce. Dissect away the surrounding tissue and locate the duct and its opening. Each gland is dorsoventrally flattened, rounded anteriorly, and tapers back to the edge of the foreskin. Insert a fine pair of scissors into the orifice of the duct and slit it lengthwise. Note the relatively very large calibre of the duct beyond the opening, and the soapy character of the contained secretion. It has been claimed that this secretion protects the integument in this region from being injured by the excretions.

The penis is the structure which is used to carry the seminal fluid from the male to the vagina of the female. 
Dissect away the muscle and connective tissue surrounding it, including the preputial glands and foreskin. The body of the penis consists of three parts, the two corpora cavernosa penis, and the corpus cavernosum urethrae. The former comprise the dorsal part of the body when in its normal position, the latter lies in a deep groove on the ventral side of the corpora cavernosa penis. Carefully separate the corpora cavernosa penis from the corpus cavernosum urethrae. Cut the former transversely. Observe that they consist of two lateral spongy masses of tissue, firmly united in the middle, but separated above by a groove carrying a blood vessel, and below by the groove inclosing the corpus cavernosum urethrae. Distally the corpora cavernosa penis terminate in one or two bones. These bones extend to the tip of the glans dorsal to the urethra when the glans is turned forward. The corpora cavernosa penis diverge proximally, forming the two crura penis. Each crus penis is a tough body firmly attached to the posterior border of the innominate bone. The corpus cavernosum urethrae terminates distally at the tip of the glans penis. Proximally it expands into a semilunar structure, probably homologous to the bulb of human anatomy. The ducts of the bulbo-urethral glands enter the urethra in front of the bulb. The urethra traverses the whole length of the corpus cavernosum urethrae and extrudes the urine or seminal fluid through the external urethral orifice.

Slit the urethra lengthwise from the external urethral orifice to the region of the prostate gland. The incision should be lateral in the vicinity of the bladder to avoid cutting into the neck of the bladder. Within the penis the lumen of the urethra is of small calibre, but between the penis and urinary bladder it expands and contains a plug of secretion. Note the diverticulum leading off into 
the bulb. Remove the plug of secretion and locate the ventral orifice through which urine enters from the bladder, also near this the openings of the ductus deferentia and ureters. Urethral glands occur in the mucous membrane of the urethra.

Exercise $X X I I I$. Make a full page drawing of the entire urogenital system of the male.

\section{THE FEMALE UROGENITAL ORGANS}

Examine the anal region of a female rat and note the three openings. At the base of the tail is the anus, ventral to it the vaginal orifice, and below this the urinary opening at the summit of a prominent elevation. As a rule there is but one external opening for the female urogenital systems in mammals.

Cautiously cut the urinary elevation lengthwise, inserting but one blade of the scissors into the urinary aperture. This elevation is homologous to the prepuce in the male. Note that it surrounds a body resembling the glans of the penis, to which it is probably homologous. One sex among animals frequently possesses rudimentary structures corresponding to functional reproductive organs in the opposite sex. The penis of the male mammal is represented in the female by the diminutive clitoris, which is terminated by the glans clitoridis, the homologue of the glans penis. A pair of prominent glands just beneath the skin correspond in position to the preputial glands of the male. Locate the opening of the duct on the inner surface of the prepuce a short distance in front of the urinary orifice. Insert a bristle into the duct, slit it open, and examine the secretion, which has a waxy feeling when rubbed between the fingers.

Clear away the muscles ventral to the pelvic girdle, slit the symphysis pubis lengthwise, and expose the female ure- 
thra. Trace it forward to the urinary bladder, and back to its entrance on the dorsal side of the preputial cavity. At the latter end insert a bristle and push it forward to the urinary bladder.

The urinary bladder is connected with the ventral wall of the abdomen by the suspensory ligament. As in the male, it temporarily stores urine which it receives through a pair of ureters, one from each kidney.

Remove the prepuce, its glans, and the clitoris. Pull the cut end of the urethra forward. This exposes the vagina. Separate the vagina from the surrounding tissues and observe that it lies immediately below the rectum. With a pair of scissors slit the vagina throughout its length. The margin of the vaginal orifice is thrown into longitudinal folds, as is also the internal surface of the vagina. The mucous membrane of the vagina is said to be without glands. The two horns of the uterus converge and join the anterior end of the vagina. The latter receives the penis of the male during copulation, and is therefore a temporary receptacle for spermatozoa. Slit each horn of the uterus a short distance in front of the vagina. Insert here a blunt probe into the lumen of each horn until the probe emerges through the external orifice (os uterus) into the vagina. There are two external orifices, one for each horn, showing that the fusion of the posterior part of the horns is superficial and does not involve the lumen (uterus duplex). The orifices are very easy to locate in an animal well advanced in pregnancy. They are surrounded by five lobes, one large dorsal lobe, one large ventral, and three smaller ventral lobes.

Each horn of the uterus is suspended from the dorsal side of the abdominal cavity by the broad ligament, which may contain considerable fat. This ligament extends an- 
terior to the ovary along the lateral surface of the kidney.

A pair of pockets, corresponding in position to the inguinal canals of the male, extends backward from the abdominal cavity. These pockets are probably the homologues of the male vaginal sacs, and therefore probably correspond to the diverticula of Nuck in man. The mesentery whose attachment runs along the posterior third of the broad ligament's lateral surface, and terminates in this diverticulum, is doubtless the round ligament. Are these diverticula found in all female rats?

Slit the anterior end of the uterus and locate the opening of the uterine (or Fallopian) tube. This tube carries the ova from the ovary to the uterus. The aperture is small but may be found fairly easily, in a uterus containing large fetuses, near the anterior end of the uterine horn, for the tube runs in the wall of the uterus a short distance before opening into it. The ovary, the gonad of the female, is incased in a tough transparent capsule, the bursa ovarica. The periovarial space lies between the bursa and the ovary. Trace the coiled uterine tube. It is said to be from two and a half to three centimeters long, and to contain from eight to ten fairly constant major loops. The tube pierces the bursa ovarica and projects into the periovarial space as the infundibulum tubae. The epithelial lining of the infundibular section of the tube bears long cilia. This is the only ciliated region of the tube. The wall of the tube contains muscles, which are best developed toward the uterine end. Slit open the ovarial capsule and observe the corpora lutea on the surface of the ovary. Each corpus luteum marks the point at which an egg bursts through the wall of the ovary during ovulation. The ovary is attached dorsally to a strong tendinous band of connective tissue which extends in the broad ligament from 
the anterior end of the uterine horn to the dorsal body wall near its union with the diaphragm.

The ovary of most mammals is not inclosed in a capsule. The ova which break through the wall of the ovary pass directly to the opening (ostium abdominale) of the uterine tube, and are then carried by cilia in the tube to the uterus. The following events, however, are said to accompany ovulation in the rat. The periovarial cavity is filled with fluid at the time of ovulation. The bursa ovarica exerts pressure upon this fluid as the result of the contraction of the muscles located near the infundibulum tubae and the attachments of the uterine tube. Simultaneously muscular contractions expand the opening (ostium) of the infundibulum tubae. Thus the fluid within the bursa ovarica, with the contained eggs, is forced into the uterine tube, where muscular contractions, possibly assisted to some extent by ciliary action, carry them to the uterus.

The fertilized egg is implanted in the wall of the uterus, where it develops. Examine a female rat with well advanced fetuses in the uterus. Note the large size of the uterus, its abundant blood supply, and segmental character. Each segment contains a fetus. Slit a segment lengthwise along its ventral surface and expose the fetus. This is covered with a thin membrane, the amnion. Carefully open the amnion along the back of the fetus. The fluid in the amniotic eavity protects the embryo from sudden jars. Note the discoidal placenta on the dorsal side of the uterus. The umbilical cord connects the belly of the embryo with the center of the placenta. The blood of the fetus passes through the umbilical cord to and from the placenta, where by osmosis. it receives nutriment from the maternal blood and surrenders waste materials to the mother's blood. The blood of fetus and mother do not mix in the placenta, but are everywhere separated from each 
other by thin membranes. Compare the fetus with the adult, with other rat fetuses of different ages, and if possible with fetuses, or models of them, of other mammals.

Exercise $X X I V$. Make a full-page drawing of the entire urogenital system of the female. 


\section{THE VASCULAR SYSTEM (Continued)}

\section{VEINS POSTERIOR TO THE HEART *}

Blood from the parts of the rat posterior to the heart enters the right auricle through the inferior vena cava (post cava). Trace the vena cava caudally to the diaphragm, which it pierces, then enters the abdominal cavity. In the thoracic cavity the vein is surrounded by the lobes of the lungs, and lies at the right of the esophagus.

Study the structure and attachments of the diaphragm. It comprises a central V-shaped tendinous portion, surrounding which is a muscular region with fibers radiating from the central tendon to the adjacent body walls. Note the relative positions of the apertures through which the inferior vena cava, esophagus, and descending aorta penetrate the diaphragm. Observe the number and distribution of the phrenic veins which traverse the diaphragm, carrying blood from its substance to the inferior vena cava. Follow the inferior vena cava posteriorly from the diaphragm, exposing its tributaries, which are described below.

The hepatic veins convey the blood from the liver, which received it from the portal circulation and hepatic artery, to the inferior vena cava. The hepatic veins may be exposed by carefully chipping away the brittle tissue of the liver with a blunt instrument. Determine the number and location of these veins. The two renal veins, short but of large calibre, drain the blood from the kidneys into the

* Locate the sympathetic nervous system before dissecting the arteries and veins posterior to the heart. This system will probably be injured during the dissection. 
inferior vena cava. As the right kidney lies anterior to the left, so the right renal vein joins the inferior vena cava anterior to the left renal. Locate and trace the suprarenal veins, which drain the suprarenal glands. The two ovarian veins pass from the vicinity of the ovary, along the broad ligament of the uterus, in company with the ovarian arteries, thence along the dorsal side of the abdominal cavity. The left ovarian vein joins the left renal vein, the right ovarian opens into the inferior vena cava some distance caudad to the right renal vein. Do you find spermatic veins corresponding in general location to the ovarian veins? In other mammals, the cat and man for instance, right and left spermatic veins are present which open into the inferior vena cava and left renal veins, respectively. The right and left iliolumbar veins join the inferior vena cava in the lumbar region. They accompany the corresponding iliolumbar arteries. Follow the course of each vein from its mouth caudolaterally across the dorsal surface of the abdominal cavity.

Trace the inferior vena cava caudally to the region where it is formed by the confluence of the right and left common iliac veins. Follow each common iliac distally to its bifurcation into the external iliac and hypogastric (internal iliac) veins. The latter may be traced dorsally into the mass of muscle, then posteriorly close to the median surface of the pelvic girdle. The external iliac vein gives off several branches, one of which, the femoral vein, accompanies the femoral artery along the inner portion of the thigh. Note any veins which carry blood away from the urogenital organs. Locate the junction of the middle sacral vein with the dorsal side of the inferior vena cava near the union of the latter with the common iliac veins. Trace the caudal vein posteriorly through the pelvic region ventral to the sacrum. 
Carefully clear away the tissues in which the inferior vena cava is imbedded and find the lumbar veins, which join the dorsal side of the inferior vena cava. Note their number, position, and distribution.

Exercise $X X V$. Make a full-page drawing of the veins anterior and posterior to the heart, incorporating the sketch required by Exercise XIV.

\section{ARTERIES POSTERIOR TO THE HEART}

The descending aorta is the posterior continuation of the aortic arch. It courses caudally through the thorax and abdomen, ventral to the vertebral column, carrying blood to the body walls, viscera, hind limbs, etc. Its position and conspicuous size make its identification easy. The main branches are as follows, beginning at the anterior end of the series.

The paired intercostal arteries pass dorsally from the thoracic section of the aorta to the muscles between the ribs. Determine the number, arrangement, and distribution of these arteries.

The first large artery leaving the dorsal aorta after it enters the abdominal cavity is the coeliac. Passing ventrally, this divides into three branches: the splenic, the hepatic, and left gastric arteries. The splenic artery splits into several branches which terminate in the spleen. It sends smaller rami to the pancreas and stomach. The hepatic artery, some distance from its origin, delivers blood to the following branches. The right gastric artery goes to the region of the pylorus, thence along the lesser curvature of the stomach, and anastomoses with the left gastric artery, which is described below. The right gastro-epiploic artery passes to the greater curvature of the stomach. The superior pancreatico-duodenal artery courses along the 
duodenum, to which it sends branches. The right gastroepiploic and superior pancreatico-duodenal arteries may arise from the hepatic artery by a short gastro-duodenal artery. Still another branch supplies the pancreas. After giving off the above vessels, the hepatic artery passes anteriorly and breaks up into several branches which enter the liver. The left gastric artery runs to the lesser curvature of the stomach. A large terminal branch supplies the dorsal surface of the stomach, another goes to the ventral surface of this organ. Small vessels are given off to the esophagus. A small branch traverses, to the right, the lesser curvature of the stomach, and anastomoses with the right gastric artery, as previously mentioned. Determine the variability of the branches of the coeliac.

The superior mesenteric artery leaves the dorsal aorta a short distance posterior to the coeliac in the region of the renal arteries. It sends numerous branches through the mesenteries to all the divisions of the small intestine, to the caecum, and the colon. The branch to the colon joins the inferior mesenteric artery.

The two large renal arteries carry blood from the dorsal aorta to the kidneys. The right renal supplies the right kidney, the left renal the left kidney. Each renal artery gives off anteriorly a suprarenal artery to the suprarenal gland on the same side.

The two spermatic arteries of the male rat leave the dorsal aorta a short distance caudad to the renals and course posteriorly along the dorsal surface of the abdominal cavity. The right spermatic finally enters the right testis, the left spermatic artery the left testis. Expose each artery throughout its length. The two ovarian arteries of the female similarly supply the ovaries. They correspond in position to the spermatic arteries of the male. Each ovarian artery anastomoses with the uterine artery, which runs 
parallel to the horn of the uterus in the broad ligament. Trace the uterine artery caudally to its origin.

The two iliolumbar arteries pass laterally in the lumbar region from the dorsal aorta, along the dorsal surface of the abdominal cavity, giving off branches to the muscles of the back. Trace the terminal branches.

The inferior mesenteric artery branches from near the posterior end of the dorsal aorta, sends branches to the rectum and descending colon, passes anteriorly along the latter, and anastomoses with the superior mesenteric artery. Is this anastomosis always present?

The aorta bifurcates at its posterior extremity, forming the right and left common iliac arteries. These give off dorsal branches to the muscles of the back, then divide into the external and internal iliac (hypogastric) arteries. The latter, which runs dorsally, divides into two main branches, one which passes laterally to the proximal region of the thigh, while the other passes caudally through the pelvic region. Dissect out these branches. The external iliac artery passes to the median surface of the thigh, there becoming the femoral artery. This gives off the saphenous artery, then penetrating the thigh it courses distally to the foot, supplying branches to the muscles of the thigh and shank. Trace the saphenous along the median surface of the shank, and note that its terminal branches enter the foot.

The middle sacral artery arises from the dorsal aorta near its posterior end and proceeds caudally through the pelvic region into the tail. Trace it and observe its branches.

The unpaired lumbar arteries pass dorsally from the abdominal section of the dorsal aorta. They correspond to the intercostal arteries of the thoracic region. The lumbar arteries bifurcate ventral to the vertebral column, 
the branches of each artery proceding dorsally on each side of the column. Determine the number of lumbar arteries, and follow them into the dorsal musculature of the lumbar region.

Exercise $X X V I$. Make a full-page drawing of the arteries anterior and posterior to the heart, incorporating the sketch required by Exercise XV. 


\section{THE NERVOUS SYSTEM}

The nervous system controls most of the activities of the rest of the organism. It receives through the sense organs the stimuli from the organs of the body and the external world, transmits them as nervous impulses, coordinates them, and originates impulses which it carries to the muscles, glands, etc., stimulating these structures to action. It comprises the following parts: (1) central nervous system (brain and spinal cord), (2) peripheral nervous system (spinal and cranial nerves, and the sympathetic nervous system), and (3) the sense organs.

\section{THE CENTRAL NERVOUS SYSTEM}

The early embryonic central nervous system of vertebrates is a comparatively simple tube (neural tube). The anterior portion develops into the brain, the remainder into the spinal cord. The embryonic brain at first comprises three divisions-in front the prosencephalon, then the mesencephalon, and posteriorly the rhombencephalon. The prosencephalon further differentiates into the telencephalon (which includes the cerebral hemispheres) and the diencephalon. The mesencephalon forms dorsally the optic lobes (corpora quadrigemina), while the rhombencephalon is transformed into the metencephalon (cerebellum and pons) anteriorly and the myelencephalon (medulla oblongata) posteriorly. The cavities of the brain are derivatives of the lumen of the neural tube.

The brain fills the cranial cavity. It has already been adequately preserved by chipping away a part of the roof 103 
of the cranium and immersing the animal in the formalin solution. Dissect away the muscles on one side of the head, preserving all nerves found. Remove the dorsal and posterior walls, and one lateral wall of the cranium, taking care not to tear the cranial nerves from the brain. Observe the connective tissue coverings (meninges) of the brain. The dura mater is the tough membrane just beneath the bone. Remove it. The pia mater is the delicate membrane, containing blood vessels, resting directly upon the brain. Between these is the arachnoid layer.

The olfactory lobes are a pair of elongated structures lying between the eyes at the anterior end of the brain. The cerebrum is the large heart-shaped section lying immediately behind the olfactory lobes. It consists mostly of two lateral hemispheres separated by the longitudinal fissure. The cerebellum is the ovoid structure posterior to the cerebrum. It includes the median vermis and the right and left hemispheres. Observe the transverse furrows on both vermis and lobes. The medulla oblongata succeeds the cerebellum and joins the spinal cord posteriorly. Compare the cerebral hemispheres of the rat with those of the dog, eat, man, or other higher mammal. The rat's cerebrum lacks the grooves (sulci) and ridges (gyri) found in these other forms.

Clear away the blood vessels on the surface of the brain. The longitudinal fissure widens posteriorly, exposing the corpora quadrigemina (optic lobes). The pineal body (epiphysis) is the globular structure at the posterior end of the longitudinal fissure. Carefully press aside the hemispheres and observe that of the four lobes of the corpora quadrigemina, two are on the right, and two are on the left. The anterior pair are the superior colliculi, the posterior are the inferior colliculi. The cerebral hemispheres are connected with each other by the corpus callosum, a broad white 
sheet which will be observed in front of the corpora quadrigemina when the hemispheres are pressed apart.

The paraflocculus projects laterally from the lateral lobe of the cerebellum. Cautiously remove the petrotympanic bone, a bit at a time, and note that the paraflocculus occupies the floccular fossa (see the petrotympanic bone). The paraflocculus resembles a toadstool, the enlarged distal end lying in the fossa. The flattened floccus proper is anteroventral to, and in contact with, the paraflocculus.

Exercise $X X V I I$. Sketch the dorsal view of the brain.

Remove the brain from the skull, being careful to preserve the roots of the cranial nerves. Care should be taken to keep the paraflocculus intact. The connections between the cranial nerves and the brain are easily broken. If considerable care is used in dissecting away the bone around the foramina of the nerves, many of them may be removed almost entire on that side of the head where the muscles were taken away. Separate the brain from the spinal cord and immerse it in a weak formalin solution, where it may be studied.

Each olfactory lobe will now be seen to contain two parts-the olfactory bulb, and the olfactory tract. Each bulb is a swelling at the anterior end of the tract, and in a preserved specimen the former is considerably darker than the latter. The tract rests in a depression on the oblique anterior surface of the cerebral hemisphere. By its distinct whiteness each tract may be followed backward and outward to the level of the optic chiasma, where it disappears. Two pear-shaped areas darker than the olfactory tracts extend from the olfactory lobes back to the optic chiasma. They meet in the median plane, and each is limited laterally by the olfactory tract.

The optic nerves of mammals cross at the optic chiasma, 
and continue on into the brain as the optic tracts. Thus light stimuli received by the right eye may pass to the left side of the brain, and vice versa. The two white and conspicuous optic nerves run forward a short distance from the chiasma before turning outward to enter the orbits. Observe that the optic tracts diverge behind the chiasma, and are there connected with each other by a whitish band.

The infundibulum is the prominence just behind the optio chiasma. It is in contact with the pinkish hypophysis or pituitary body, which is covered by a meningeal fold, so that the hypophysis remains in the cranium when the brain is removed. The pedunculi cerebri flank the posterior part of the infundibulum, joining the cerebrum to the medulla oblongata.

The medulla is wedge-shaped, the expanded anterior end running forward beneath the cerebellum. Just behind the infundibulum a band of nervous tissue, the pons, crosses the ventral surface of the medulla, connecting the cerebellar hemispheres. Two pyramids run back from the pons along the midventral surface of the medulla.

The distribution of many of the cranial nerves can be worked out on that side of the head from which the muscles have not been removed. There are twelve pairs of these nerves, as follows.

The first cranial nerves (olfactory) consist of a number of filaments proceeding from the anterior ends of the olfactory lobes, through the cribriform plate of the ethmoid bone, to the mucous membrane of the nasal cavity. They will probably not be seen.

The second cranial nerves (optic) have already been described.

The third nerves (oculomotor) arise from the cerebral peduncles and extend anteriorly beneath the dura mater 
on the under side of the brain. They enter the orbits through the anterior lacerated foramina and innervate the superior, inferior, and internal rectus muscles, and the inferior obliques. These muscles move the eye.

The fourth nerves (trochlear) emerge from the dorsal side of the brain behind the posterior colliculus, run forward along the under surface of the cerebral hemispheres lateral to the second and sixth nerves, and enter the orbits through the anterior lacerated foramina. They innervate the superior oblique muscles of the eye.

Each of the fifth nerves (trigeminal) leaves the pons as two closely connected roots. It then divides into three branches. (1) The ophthalmic branch passes through the anterior lacerated foramen into the orbito-temporal fossa, where it sends branches to the adjacent integument, and a small nerve back into the cranium through a foramen which is anterodorsal to the optic foramen. (2) The superior maxillary is a large branch which also enters the orbito-temporal fossa through the anterior lacerated foramen, runs along the dorsal side of the alveolar process of the maxillary bone, traverses the infraorbital fissure, and terminates at the roots of the vibrissae and in the skin of the face. (3) The inferior maxillary nerve passes from the cranial cavity through the foramen ovale. Immediately after emerging from the cranium it gives off several branches to the jaw muscles, a lingual ramus to the tongue, while a large trunk enters the mandibular foramen of the mandible. This trunk traverses the dental canal, emerging by the mental foramen to pass to the skin of the lower jaw and the chin. If time permits, trace the nerve through the mandible.

The sixth nerves (abducens) start from the anterior region of the medulla oblongata, course along under the brain beside the third cranial nerves, emerge into the orbits 
through the anterior lacerated foramen and innervate the external rectus muscles of the eyes.

The seventh cranial nerves (facial) emerge from the side of the medulla behind the fifth, and leave the cranium through the facial canals just behind the external auditory meatuses. They send branches to the lateral surfaces of the muscles of mastication, where they may easily be seen when the skin is removed from the head.

The eighth nerves (acoustic) arise from the medulla oblongata behind the seventh, penetrate the auditory capsules, and reach the inner ears.

The ninth nerves (glossopharyngeal) arise from the medulla oblongata close to the tenth. Leaving the skull by the posterior lacerated foramen, they send branches to the pharynx and tongue. They are anterior to, and deeper than, the twelfth nerves, and lie close to the skull.

The tenth nerves (vagus or pneumogastric) arise from the side of the medulla oblongata posterior to the eighth, and leave the cranium through the posterior lacerated foramen. Shortly after emerging they give off the superior laryngeal nerves to the larynx, then proceed back to the thoracic cavity along the common carotid artery. The recurrent laryngeal nerve is given off near the entrance of the vagus into the thorax. Trace it forward, on both sides, along the esophagus to the larynx. On the right it turns forward from the vagus dorsal to the subclavian artery, on the left side dorsal to the aortic arch. The tenth nerves in the thorax lie dorsal to the heart and lungs, which they are said to innervate. Passing backward along the esophagus, they penetrate the diaphragm, then innervate the stomach.

The eleventh nerves (accessory) arise from the anterior region of the spinal cord, and from the medulla enter the skull through the foramen magnum, unite with the vagus 
nerves, and with them escape through the posterior lacerated foramen. Trace them to the muscles of the neck.

The twelfth nerves (hypoglossal) leave the medulla behind the first ten cranial nerves, escape from the skull through the hypoglossal canals, and may be traced easily to the ventral part of the tongue.

Exercise $X X V I I I$. Draw a ventral view of the brain, showing the origins of the cranial nerves.

Using a very sharp razor cut the brain in two along a plane parallel to, and a millimeter or two at the left of, the longitudinal fissure. Place the larger piece in water and cautiously dissect away the remnants of the left half of the brain, exposing the structures described below.

The corpus callosum is the thick commissure connecting the cerebral hemispheres. Posteriorly it takes the form of an oval mass (splenium); anteriorly it bends downward (genu), forming the rostrum. This section exposes a region of the brain not observed on the dorsal side of the organ-the thalamencephalon, or diencephalon. The diencephalon of the dogfish, frog and other lower vertebrates is visible dorsally, but in mammals the backward extension of the cerebral hemispheres, which is in general coincident with the development of higher intelligence, conceals the diencephalon.

The third ventricle is the cavity within the diencephalon. The fornix is dorsal to this ventricle. From its union, posteriorly, with the corpus callosum, the fornix runs forward and downward anterior to the third ventricle. Observe the anterior commissure at the lower end of the fornix. The lamina terminalis is the anterior boundary of the third ventricle. The conspicuous intermediate mass, or middle commissure, extends from one lateral wall to the diencephalon to the other through the third ventricle. The in- 
fundibular recess is the extension of the ventricle into the infundibulum. Posteriorly the ventricle opens into the cerebral aqueduct (aqueduct of Sylvius), which leads back through the mesencephalon to the fourth ventricle, the cavity under the cerebellum and in the medulla oblongata. The aqueduct may be seen best in a transverse section through the corpora quadrigemina, where it will be seen as a narrow vertical slit.

The corpora quadrigemina will be seen above the aqueduct. (Compare them with the optic lobes of the dogfish.) Observe that the superior colliculi are longer than the inferior. The isthmus is the deep dorsal fissure that separates the corpora quadrigemina from the cerebellum.

In the sectioned cerebellum note the deep fissures (sulci) which separate the prominent folds (gyri). The gray matter of the cerebellum is on the surface of the gyri, and so completely penetrates the white matter that the latter resembles the branches of a tree, and is therefore called the "arbor vitae."

The fourth ventricle is covered dorsally by the anterior, and the posterior medullary velum, both thin membranes underlying the cerebellum. The former extends from the base of the arbor vitae forward to the inferior colliculus, while the latter spreads backward.

The cerebellum is strongly attached by the peduncles to the medulla on each side. Locate these attachments by dissecting away the peripheral tissue on the under side of the cerebellum. The lateral fibrous tract (brachium pontis or middle peduncle), which runs anteroventrally along the lateral surface of the medulla, enters the pons. The median tract (brachium conjunctivum or anterior peduncle) goes forward toward the corpora quadrigemina. The posterior peduncle appears as a ridge passing back to the dorsal side of the medulla. These tracts may be seen more clearly 
if they be severed at their union with the cerebellum by a horizontal stroke with a sharp razor.

Clear away the tissue on the dorsal and lateral side of the cerebral hemisphere, exposing the corpus callosum. Trace it into the hemisphere. Cut through the corpus callosum, expose the cavity of the hemisphere (lateral ventricle), and open this ventricle throughout its extent. The anterior horn of the ventricle runs ventrally, bounded medially by the septum pellucidum, and laterally by the convex corpus siriatum. The remainder of the cavity follows a curvilinear course, at first posteriorly and laterally, and finally ventrally, terminating near the infundibulum. From the corpus striatum backward the hippocampus forms the median wall of the ventricle. The lateral surface of the hippocampus is convex. Viewed from above it forms an angle of about forty-five degrees with the long axis of the brain; from the side it is approximately $U$ shaped. The lateral and third ventricles communicate through the interventricular foramina (foramina of Munro).

Exercise $X X I X$. Sketch a sagittal section of the brain.

\section{THE SYMPATHETIC NERVOUS SYSTEM}

The sympathetic nervous system regulates the distribution of blood in the body through its control over the nonstriated muscle tissue in the walls of the blood vessels. This regulation is accomplished through variation in the calibre of the vessels, brought about by the contraction and relaxation of these muscles. Sympathetic fibers innervate also the respiratory, reproductive, digestive, and other organs, together with their glands. The motor activities of the system are beyond the control of the will, and the stimulation of its sensory structures does not necessarily induce conscious states. 
The sympathetic system of mammals is centralized in a pair of ganglion-bearing, longitudinal sympathetic trunks, one on each side of the vertebral column. This trunk connects with the spinal cord through the spinal nerves, and also sends fibers to sympathetic plexuses in various parts of the body. These plexuses in turn send nerves to the viscera. Locate the two longitudinal sympathetic trunks in the rat, one on each side of the vertebral column. Trace one of these anteriorly to the head and posteriorly to the pelvic region. The superior cervical ganglion is a spindle-shaped enlargement near the bifurcation of the common carotid artery. The cervical portion of the trunk is dorsal to the tenth eranial nerve. The inferior cervical ganglion is the swelling of the trunk at the base of the neck. The thoracic section lies ventral to the ribs and presents ganglionic enlargements. The lumbar portion is median to the dorsal muscle mass in the lumbar region. Locate if possible the splanchnic nerves, which leave the thoracic ganglia in the vicinity of the eleventh and twelfth ribs, enter the abdomen, and go to the solar plexus. Find other rami of the sympathetic trunk.

\section{THE SPINAL NERVES}

The study of the spinal cord and the spinal nerves leading from it should be postponed until dissections and drawings of all other parts of the body, including the sympathetic system, have been completed. Expose the spinal nerves by carefully dissecting away the muscles ventral and lateral to the backbone, from the occipital region of the head to the base of the tail. The spinal nerves are designated according to the region in which they are found, cervical, thoracic, lumbar, sacral, and coccygeal.

The cervical spinal nerves, eight pairs in all, are in the neck. The first pair leaves the spinal canal through a fora- 
men in the neural arch of the atlas. The other seven pairs escape through the intervertebral foramina. The first, second, third, and part of the fourth pairs of nerves go to the neck muscles. The phrenic nerve leaves the fourth cervical nerve. Trace it caudad to the diaphragm.

Dissect the brachial plexus, the conspicuous bundle of intercommunicating nerve trunks in the axillary region. It is formed by the fourth, fifth, sixth, seventh, and eighth cervical, and the first dorsal nerves. Note the size of these nerves. The brachial plexus sends the following branches to the arm. (1) The ulnar nerve goes to the posterior region of the forearm. (2) The median nerve runs across the anterior surface of the elbow joint, supplying the muscles of the inner side of the arm. (3) The axillary nerve passes around the posterior side of the humerus, crosses the elbow joint, and as the radial nerve proceeds to the outer side of the arm. Locate, also, the branches going from the plexus to the thorax.

There are thirteen pairs of thoracic spinal nerves. The first enters the brachial plexus. The second to the twelfth inclusive run in the muscle tissue between the ribs. The thoracic nerves leave the spinal canal through the intervertebral foramina. Except for the first, they innervate the walls of the thorax and anterior part of the abdomen.

The six pairs of lumbar nerves are associated with the thick muscle masses in the lumbar and sacral regions. Carefully remove these muscles without severing the nerves or their connections. The first two pairs of lumbar nerves innervate the abdominal walls, by way of the lumbar plexus. Find the lumbar plexus, which is formed on each side by part of the first, second, third, fourth, and fifth lumbar nerves. The three following nerves arise from it. The femoral nerve proceeds caudally to the inner aspect of the hind limb. The obturator nerve passes through the obtura- 
tor foramen of the coxal bone to the adjacent muscles. The sciatic nerve may be traced from the lumbar plexus to the deeper posterior muscles of the thigh.

The remainder of the fifth lumbar nerve, and the sixth lumbar nerve, together with part of the first and second sacral nerves, form the sacral plexus. There are four pairs of sacral nerves. Locate the caudal nerve in the tail and trace it forward to its connections with the sacral nerves.

Exercise $X X X$. Sketch the spinal and sympathetic nerves of one side of the body.

\section{THE SPINAL CORD (SPINAL MEDULLA)}

Clear away the muscles surrounding the backbone and sever the head from the body at the articulations between the cranium and the atlas. Carefully expose the spinal cord throughout its length by removing the roof of each neural arch. The cord is surrounded by tough membranes, the meninges.

Observe the connections of several of the spinal nerves with the cord. Each nerve proceeds from the cord as a pair of roots, a dorsal and ventral. The former bears a swelling, or ganglion. Trace a pair of roots from their origin to the point where they unite to form the spinal nerve. The dorsal ganglia in mammals contain the cell bodies of sensory neurons which send some of their fibers through the dorsal root to the spinal cord, and other fibers distally to the spinal nerve. The dorsal root is, therefore, sensory in function. The ventral root carries motor fibers from nerve cells located in the cord itself. Thus each spinal nerve carries nervous impulses both to and from the spinal cord.

Observe the cervical and lumbar enlargements of the cord in the neck and lumbar regions, respectively. The 
former is the source of the nerves entering the brachial plexus, the latter of the fibers going to the sciatic plexus.

Remove the cord from the neural canal, strip off the meninges, and note that the cord rapidly diminishes in size in the posterior lumbar region, finally terminating in the slender thread-like filum terminale. The posterior spinal nerve roots proceed caudally, accompanied by the filum terminale, for a considerable distance from their attachment to the cord. These roots constitute the cauda equina, so called from its resemblance to a horse's tail.

Exercise $X X X I$. Draw a cross section of the spinal cord to show the origins of the spinal nerves, the spinal ganglia, etc. 



\section{INDEX}

Abdominal cavity, 59, 66. Acetabulum, 33, 35.

Acoustic meatus, 9, 18.

Acromion process, 30 .

Alveolus, 10.

Angular process, 24.

Anterior commissure, 109.

Anus, 5, 77, 92.

Aorta, 55, 99.

Aponeurosis, 39.

Appendicular skeleton, 6.

Aqueduct of Sylvius, 110.

"Arbor vitae," 110.

Artery, axillary, 56.

brachial, 57.

carotid, external and internal,

57.

left common, 55, 57.

right common, 58 .

coeliac, 99.

common iliac, 101.

costo-cervical, 56.

deep, of arm, 57.

external maxillary, 58.

facial, 58.

femoral, 101.

gastro-duodenal, 100.

hepatic, 80, 99.

hypogastric, 101.

iliac, external, 101. internal, 101.

iliolumbar, 101.

innominate, 55, 58.

intercostal, 99.

internal mammary, 55, 56, 59.

lateral thoracic, 56.

left gastric, 99 .
Artery, lingual, 58.

lumbar, 101.

mesenteric, 100, 101.

ovarian, 100.

pancreatico-duodenal, 99.

posterior auricular, 58.

pulmonary, 51.

renal, 84, 100.

right axillary, 59.

gastric, 99.

gastro-epiploic, 99.

saphenous, 101.

spermatic, 100.

splenic, 99.

subclavian, 55, 58.

subscapular, 56.

suprarenal, 100.

thyrocervical, 56.

uterine, 100.

vertebral, 56.

Arytenoid cartilage, 65.

Astragalus, 36.

Atlas, 25.

Atrial septum, 62 .

Atrium, 59.

Auditory tubes, 71.

Auricle, 59.

Auricular surface, 28, 34.

Axial skeleton, 6.

Axis, 25.

Bicuspid valve, 62.

Blood, 50, 51.

Bone, alisphenoid, 10.

basisphenoid, 10 .

earpal, 32.

cartilage, 7. 
Bone, cherron, 28.

coxal, 33.

ethmoid, 20.

frontal, 9, 19.

hyoid, 24.

innominate, 33 .

interparietal, 9, 18.

jugal, 22.

malar, 22.

maxillary, 9, 10, 20.

membrane, 7 .

metacarpal, 32 .

metatarsal, 36 .

nasal, 9, 22.

occipital, 9, 10, 15.

palatine, 10, 23.

parietal, 9, 19.

petrosal, 9, 10, 18 .

premaxillary, 9, 10.

presphenoid, 10.

sphenoid, 16.

squamosal, 9, 10, 17.

turbinal, 14.

tympanic, 18.

vomer, 22.

zygomatic, 9, 22.

Brachial plexus, 113, 115.

Brachium eonjunctivum, 110. pontis, 110.

Brain, 103.

Bronchi, 63, 64 .

Caecum, 76.

Calcaneus, 36.

Capillaries, 51.

Caput epididymidis, 86 .

Cardia, 73.

Cardiac sac, 73.

Cauda epididymidis, 87. equina, 115.

Cerebellum, 12, 103, 104.

Cerebral aqueduct, 110.

Cerebrum, 13, 104.

Cervical ganglia, 112.

Choana, 11.
Chordae tendineae, 61.

Clavicle, 30.

Clitoris, 92.

Coelom, 59.

Colliculi, 104.

Colon, 76.

Condyloid process, 24.

Coracoid process, 30 .

Coronoid process, 24.

Corpora cavernosa penis, 91 .

lutea, 94.

quadrigemina, 103, 104, 110.

Corpus callosum, 104, 109, 111.

cavernosum urethrae, 91 .

epididymidis, 86 .

striatum, 111.

Cranial cavity, 12.

Cranium, 7.

Cribriform plate, 13.

Cricoid eartilage, 65.

Crura penis, 91 .

Diaphragm, 97.

Diastema, 10, 23, 69 .

Diastole, 60.

Diencephalon, 103, 109.

Digestive system, 68 .

Digit, 4, 37.

Diverticula of Nuck, 94 .

Dorsal ganglia, 114.

Duct, bile, 80,83 .

hepatic, 80 .

naso-pharyngeal, 13.

parotid, 48.

submaxillary, 49.

Ductus deferens, 87.

Duodenocolic omentum, 81 .

Duodenum, 75.

Dura mater, 104.

Endoskeleton, 6.

Epididymis, 86.

Epiglottis, 64, 72.

Epiphysis, 104.

Epistropheus, 25. 
Erythrocytes, 50.

Esophagus, 63, 72.

Eustachian tubes, 71 .

Exoskeleton, 6.

Fallopian tube, 94.

Feces, 5, 77.

Femur, 33, 35.

Fetus, 94, 95.

Fibula, 35.

Filum terminale, 115.

Foramen, anterior lacerated, 10, 107.

atlantal, 26, 56.

carotid, 12.

interventricular, 111.

intervertebral, 27, 113.

jugular, 12.

magnum, 11, 108.

mandibular, 24.

mental, 24.

of Munro, 111.

obturator, 33.

optic, 10.

ovale, 9.

posterior lacerated, 11, 108.

postpalatine, 10, 12 .

prepalatine, 12, 14 .

transcersarium, 26.

Fornix, 109.

Fossa, cerebellar, 12.

cerebral, 12.

floccular, 13, 105.

jugular, 9.

mandibular, 18.

nasal, 14.

olecranon, 31.

olfactory, 12.

orbito-temporal, 8 .

Forea dentis, 25.

Gastric juice, 74 .

Genu, 109.

Gland (s), ampullary, 89. bulbo-urethral, $90,91$.
Gland (s), cardial, 74.

Cowper's, 90. endocrine, 53. lacrimal, 48. parotid, 48. preputial, 90 . prostate, 89 . pyloric, 74 . rennet, 74 . salivary, 48. submaxillary, 48. suprarenal, 84 . thymus, 53. thyroid, 63. vesicular, 88 .

Glans, 5. clitoridis, 92. of penis, 90 .

Glenoid eavity, 30, 31.

Glottis, 64, 72 .

Greater omentum, 81 .

Greater tuberosity of humerus, 31.

Grri, 110.

Hallux, 4, 37.

Heart, 51, 59.

Hepatic portal system, 66 .

Hilum, 84.

Hippocampus, 111.

Humerus, 31.

Hypoglossal canal, 11, 109.

Hypophysis, 106.

Ileocolic valve, 76 .

Ileum, 76.

Ilium, 33.

Infraorbital fissure, 8, 107.

Infundibulum, 106. recess of, 110 .

Inguinal canal, 85.

Intestine, 75.

Ischium, 33, 34 .

Isthmus, 110. faucium, 69. 
Jejunum, 76.

Jugular process, 9.

Kidney, 84, 85, 93.

Lambdoidal ridge, 8.

Lamina, 25. terminalis, 109.

Larynx, 63, 64.

Lateral malleolus, 36.

Lesser tuberosity, 31.

Ligament, broad, of uterus, 93. falciform, 79 .

gastrosplenic, 81 .

round, 35, 77, 80, 94.

suspensory, 93.

triangular, 80.

Linea alba, 47.

Liver, 77.

Lumbar plexus, 113.

Lung, 64.

Lymph, 50.

vessels, 51.

Mandible, 23.

Mandibular symphysis, 23.

Medial malleolus, 36 .

Mediastinal septum, 52, 63.

Medulla oblongata, 103, 104, 106.

Meninges, 104, 114.

Mesencephalon, 103, 110.

Mesenteries, 80.

Mesocolon, 80, 81 .

Mesoduodenum, 82.

Mesogastrium, 80.

Metacromion process, 30 .

Metencephalon, 103.

Middle commissure, 109.

Mitral orifice, 62.

valve, 62 .

Mouse, 2.

Mouth cavity, 69.

Muridae, 2.

Mus, 2, 3.

Muscle, abductor, 40.
Muscle, acromiodeltoideus, 43. acromiotrapezius, 42. adductor, 40 .

biceps femoris, 45 .

elavotrapezius, 42 .

cremaster, 85.

cutaneous maximus, 41.

depressor, 40.

digastricus, 45 .

dilator, 40.

extensor, 40.

external oblique, 44.

rectus, 108.

flexor, 40.

glutaeus maximus, 45.

inferior oblique, 107.

insertion, 39.

latissimus dorsi, 43.

levator, 40.

auris longus, 42.

masseter, 41.

omohyoideus, 46.

origin, 39.

papillary, 61.

pectoralis major, 46.

minor, 46.

platysma, 41.

quadratus labii superioris, 42.

rectus abdominis, 46.

rotator, 40 .

semitendinosus, 45 .

of skin, 41 .

sphineter, 40.

spinodeltoideus, 43.

spinotrapezius, 43.

sternohyoideus, 46.

sternomastoideus, 43.

superior oblique, 107.

temporal, 42.

tensor fasciae latae, 45 .

triceps brachii, 44.

Myelencephalon, 103.

Nares, 8, 11.

Nasal cavity, 12. 
Nasal labyrinth, 14. septum, 14, 20.

Nasopharynx, 71.

Nerve, abducens, 107. accessory, 12, 108. acoustic, 108 . axillary, 113. caudal, 114. cervical spinal, 112. eranial, 12. eighth cranial, 108. eleventh cranial, 108. facial, 108. femoral, 113. fifth cranial, 107. first cranial, 106. fourth cranial, 107. glossopharyngeal, 12, 108. hypoglossal, 109. lumbar, 113. ninth cranial, 108. oculomotor, 106. olfactory, 13, 106. optic, 105, 106. pneumogastric, 108. sacral, 114. sciatic, 114. second cranial, 106. seventh cranial, 108. sixth eranial, 107. spinal, 112.

tenth eranial, 108. third cranial, 106. thoracic spinal, 113. trigeminal, 107. trochlear, 107. twelfth cranial, 109. vagus, 12, 108.

Neural arch, 25. spine, 25.

Nuchal surface, 8.

Occipital condyle, 9, 11. Odontoid process, 25. Olecranon, 32.
Olfactory bulb, 105. lobes, 104. tract, 105.

Optic chiasma, 105. lobes, 103, 104. tracts, 106.

Os uterus, 93.

Ostium abdominale, 95.

Ovary, 94.

Ovulation, 95.

Palate, 11, 69, 71.

Palatine arch, 70.

Pancreas, 83.

Patella, 36.

Pedicle, 25.

Peduncles of cerebellum, 110.

Pelvic girdle, 33.

Penis, 5, 90, 93.

Pericardium, 52, 59.

Phalanges, 32, 37.

Pharynx, 72.

Pia mater, 104.

Pillar of the fauces, 70 .

Pineal body, 104.

Pituitary body, 106.

Pleura, 63.

Plexus, sacral, 114. sciatic, 115.

Pollex, 4.

Pons, 103, 106.

Posttympanic hook, 9, 17.

Postzygapophysis, 25.

Prepuce, 5, 90.

Prezygapophysis, 25.

Prosencephalon, 103.

Pterygoid process, 9, 11.

Pubis, 33, 34.

Pulmonary orifice, 61. valve, 61.

Pylorus, 73, 74.

Pyramids, 106.

Radius, 31 .

Rat, 2, 3, 
Rectum, 77, 93.

Rhombencephalon, 103.

Ribs, 28, 29.

Rodentia, 1.

Rostrum, 109.

Sacrum, 28.

Seapula, 30.

Scapular spine, 30 .

Scrotum, 5, 85.

Semilunar notch, 32.

Seminiferous tubules, 87.

Septum pellucidum, 111. scroti, 86.

Skull, 6.

Spinal cord, 25, 112, 114.

Spinous process, 25.

Spleen, 81.

Splenium, 109.

Sternum, 28.

Stomach, 73.

Styloid process, 32.

Sulci, 110.

Sympathetic trunks, 112.

Systole, 60.

Talus, 36.

Tarsus, 36.

Teeth, incisor, 10, 69 .

molar, 10, 69.

Telencephalon, 103.

Temporal line, 8, 19.

Tendon, 39.

Tentorium, 13.

Testes, 5, 85 .

Thalamencephalon, 109.

Thorax, 29, 59.

Thyroid cartilage, 65 .

Tibia, 35.

Tongue, 70, 71.

Tonsil, 71.

Trabeculae carneae, 61 .

Trachea, 63.

Transverse process, 25.

Trochanters, 35 .
Tunica albuginea, 87 . vaginalis, 87 .

Tympanic bulla; 9, 18. membrane, 9 .

Ulna, 31, 32.

Umbilical cord, 95.

Ureter, 84, 89, 93.

Urethra, 88, 89, 90. female, 92 .

Urethral orifice, external, 91.

Urinary bladder, 89.

Uterine tube, 94.

Uterus, 93.

Vagina, 90, 93.

Vaginal orifice, 5, 92.

Valve, tricuspid, 61.

Vein, angular, 54. anterior auricular, 54. facial, 54 .

jugular, 54 .

azygos, 53.

cephalie, 53.

common iliac, 98.

external iliac, 98. jugular, 53.

femoral, 98.

gastro-epiploic, 66.

gastrosplenic, 66 .

hepatic, 80, 97.

hypogastric, 98 .

iliolumbar, 98.

inferior mesenteric, 67 .

internal iliac, 98.

jugular, 53 .

internal mammary, 53.

maxillary, 54, 55.

lumbar, 99.

ovarian, 98.

pancreatico-duodenal, 66.

portal, 66, 80 .

posteaval, 97.

posterior facial, 54 . 
Vein, precaval, 53. pulmonary, 51. renal, 84, 97. subclavian, 53. superficial temporal, 54 . superior mesenteric, 66 . supraorbital, 54 . suprarenal, 98. transverse facial, 54.

Vena cara, inferior, 97. superior, 53.

Ventricles of brain, 109, 110, 111. of heart, 59 .
Ventricular septum, 62.

Vermis of cerebellum, 104 .

Vertebrae, 25, 26, 27, 28.

Vertebral arch, 25. column, 24. foramen, 25.

Vertebrarterial canal, 27, 56.

Vestibule, 69.

Vibrissae, 4.

Visceral skeleton, 7 .

Vocal cords, 64 .

Zygomatic arch, 8. 





4.

$a^{2}$

4

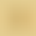

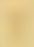

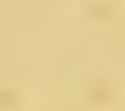

.

(n) 4

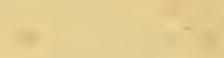

$=$ v

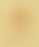

\begin{abstract}
、
\end{abstract}

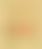

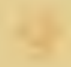

$+2$

.

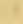


9 